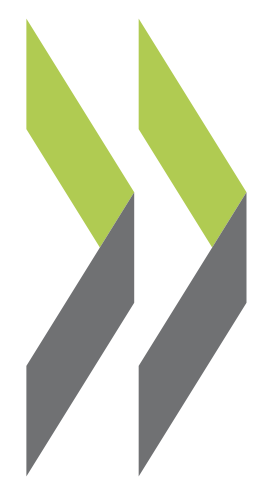

OECD Science, Technology and Industry Working Papers $2007 / 04$

Capturing Nanotechnology's Current State of Development via Analysis of Patents
Masatsura Igami, Teruo Okazaki 
Organisation de Coopération et de Développement Economiques

Organisation for Economic Co-operation and Development

23-May-2007

DIRECTORATE FOR SCIENCE, TECHNOLOGY AND INDUSTRY

English - Or. English

CAPTURING NANOTECHNOLOGY'S CURRENT STATE OF DEVELOPMENT VIA ANALYSIS OF PATENTS

STI WORKING PAPER 2007/4

Statistical Analysis of Science, Technology and Industry

Masatsura Igami and Teruo Okazaki 


\section{STI Working Paper Series}

The Working Paper series of the OECD Directorate for Science, Technology and Industry is designed to make available to a wider readership selected studies prepared by staff in the Directorate or by outside consultants working on OECD projects. The papers included in the series cover a broad range of issues, of both a technical and policy-analytical nature, in the areas of work of the DSTI. The Working Papers are generally available only in their original language - English or French - with a summary in the other.

Comments on the papers are invited, and should be sent to the Directorate for Science, Technology and Industry, OECD, 2 rue André-Pascal, 75775 Paris Cedex 16, France.

The opinions expressed in these papers are the sole responsibility of the author(s) and do not necessarily reflect those of the OECD or of the governments of its member countries.

\section{http://www.oecd.org/sti/working-papers}


DSTI/DOC(2007)4

\title{
CAPTURING NANOTECHNOLOGY'S CURRENT STATE OF DEVELOPMENT VIA ANALYSIS OF PATENTS ${ }^{1}$
}

\author{
Masatsura IGAMI, OECD (masatsura.igami@oecd.org) \\ and \\ Teruo OKAZAKI, OECD (teruo.okazaki@oecd.org)
}

\section{MAIN FINDINGS}

This analysis aims at capturing current inventive activities in nanotechnologies based on the analysis of patent applications to the European Patent Office (EPO). The main findings are the following:

\section{Nanotechnology: a set of technologies on the nanometre scale, not a single technological field}

- Nanotechnology is a multifaceted technology. At present, it consists of a set of technologies on the nanometre scale rather than a single technological field. It covers "Electronics", "Optoelectronics", "Medicine and biotechnology", "Measurements and manufacturing", "Environment and energy", and "Nano materials".

- The majority of nanotechnologies, especially nanotechnologies related to "Electronics" and "Optoelectronics", are seemingly realised by a top-down process, where nano-structures are developed through the improvement or advancement of existing technologies. Mutual interactions among these top-down nanotechnologies appear to be weak, because they are usually pushing the technological frontier within their own fields. As they build on cumulative knowledge, top-down nanotechnologies are likely to have social and economic impacts in the short and medium term.

- Another group of nanotechnologies is developed by a bottom-up process. The development of such technologies has been particularly intense in the past decade and fuelled by scientific discoveries such as carbon nanotubes and fullerenes. The increasing importance of "Measurements and manufacturing" in the development of bottom-up nanotechnology was also observed. At this stage, bottom-up

1. The paper was prepared under the supervision of Dominique Guellec, DSTI, and benefited from valuable comments by Colin Webb, Pluvia Zuniga, Hélène Dernis, Anthony Arundel, Alessandra Colecchia, Dirk Pilat and Yoshiaki Tojo of DSTI. 


\section{DSTI/DOC(2007)4}

nanotechnology is likely to have a relatively low impact on application fields. It will take a while until bottom-up nanotechnologies have social and economic impacts.

- Nanotechnology not only covers a wide range of technologies, but also underpins the development of many fields. High citations of nanotechnology patent applications are likely to point to their high technological or economic value.

\section{The recent rise of inventive activities in nanotechnology}

- Nanotechnology patent applications to the EPO have been increasing since the 1980s, apart from a temporary stagnation in the early 1990s. The increase, especially remarkable since the end of the 1990 s, has been higher than the average growth in the total number of EPO applications.

- The United States, the European Union and Japan have almost the same share in nanotechnology patent applications to the EPO, with the United States and Japan holding a relatively higher share compared to their total EPO average.

- Higher education and government sectors are an important source of knowledge in nanotechnology. Their shares in nanotechnology patent applications are notably larger than in the EPO average for all patent applications. The contributions of these sectors have become particularly important since the middle of the 1990s. Because of differences in national science, technology and innovation systems, the shares of government and higher education sectors vary across countries. The share of the government sector is the largest in France and Japan. The higher education sector holds a relatively large share in the United Kingdom, the United States and the Netherlands. The private non-profit sector holds the largest share in Germany.

- The current development of nanotechnology relies strongly on countries' existing technologies and accumulated scientific knowledge. Japan has the largest share in "Electronics", "Optoelectronics", and "Environment and energy". The United States holds the largest share in "Medicine and biotechnology", "Measurements and manufacturing", and "Nano materials". Countries' shares in the nanotechnology patent applications in each application field are strongly correlated with their shares in non-nanotechnology patent applications of the same fields, except for the European Union. Other countries are increasingly contributing to nanotechnology inventive activities, especially Korea which holds the fourth largest share in nanotechnology related to "Electronics".

\section{Science fuels technological development in diverse ways}

- Science fuels nanotechnology in diverse ways. An analysis of citations to non-patent literature shows the importance of interactions between scientific and inventive activities in nanotechnology. Three typologies of interactions can be distinguished. First, some inventive activities are spurred by scientific activities. These technologies show a relatively large share of non-patent literature in the initial stage of development, e.g. semiconductor devices. Second, some technologies are continuously fuelled by science, as revealed by their almost constant share of non-patent literature, e.g. drug delivery and applications of titanium dioxide to sun screening. Finally, there are some technologies for which the linkage between science and technology becomes important over time, e.g. carbon nanotubes.

- Scientific activities have a crucial role in knowledge creation and flows in nanotechnology. Measurements of citation time-lags showed a remarkable shortening of the time-lags sparked by scientific breakthroughs, e.g. the discovery of carbon nanotubes. Citation analysis shows that the higher education sector produces a relatively high share of frequently cited patent publications. 
DSTI/DOC(2007)4

\title{
NANOTECHNOLOGIES : ÉTAT DES LIEUX DRESSÉ À PARTIR D'UNE ANALYSE DES BREVETS ${ }^{2}$
}

\author{
Masatsura IGAMI, OCDE (masatsura.igami@OCDE.org) \\ et \\ Teruo OKAZAKI, OCDE (teruo.okazaki@OCDE.org)
}

\section{PRINCIPAUX RÉSULTATS}

L'analyse présentée a pour objet de mettre en évidence les activités d'invention conduites à l'heure actuelle dans le domaine des nanotechnologies à partir d'une analyse des demandes de brevets déposées auprès de l'Office européen des brevets (OEB). Ses principales conclusions sont les suivantes :

\section{Les nanotechnologies : un ensemble de technologies opérant à l'échelle du nanomètre, et non un champ technologique spécifique}

- Les nanotechnologies sont très diversifiées, et désignent aujourd'hui un ensemble de technologies concernant l'échelle du nanomètre, et non à proprement parler un champ technologique. Elles recouvrent des domaines aussi variés que «l'électronique », "l'optoélectronique », " la médecine et les biotechnologies », «les procédés de mesure et de fabrication », «l'environnement et l'énergie » ou « les nanomatériaux ».

- La majorité des nanotechnologies, en particulier celles liées à «l'électronique» et à «l'optoélectronique », relève apparemment d'une démarche dite descendante ou «top down», qui permet de fabriquer des nanostructures grâce au perfectionnement ou aux progrès de technologies existantes. Il ne semble guère exister d'interactions entre ces différentes nanotechnologies car les avancées technologiques sont généralement opérées dans leurs champs respectifs. La connaissance dans ces domaines étant cumulative, les nanotechnologies de type «top down » auront probablement des incidences économiques et sociales à court et moyen terme.

- Il existe par ailleurs un groupe de nanotechnologies qui relève d'une démarche dite ascendante ou «bottom up ». Au cours de ces dix dernières années, le développement de ces technologies a suscité une intense activité alimentée par des découvertes scientifiques, comme les nanotubes de carbone et

2. Ce document, qui a été établi sous la supervision de Dominique Guellec (DSTI), a bénéficié des précieux commentaires apportés par Colin Webb, Pluvia Zuniga, Hélène Dernis, Anthony Arundel, Alessandra Colecchia, Dirk Pilat et Yoshiaki Tojo (DSTI). 


\section{DSTI/DOC(2007)4}

les fullerènes. On a en outre observé l'importance croissante des «procédés de mesure et de fabrication » pour la mise au point de nanotechnologies de type «bottom up ». Au stade actuel, ces technologies ne devraient guère bouleverser les champs d'application, et il faudra encore un certain temps avant qu'elles aient des effets économiques et sociaux patents.

- Les nanotechnologies ne concernent pas seulement un large éventail de technologies, elles sont la clé du développement de nombreuses disciplines. Le taux de citation élevé des demandes de brevets portant sur les nanotechnologies devrait signer leur valeur technologique ou économique.

\section{La multiplication des activités inventives dans le domaine des nanotechnologies}

- Les demandes de brevets déposées auprès de l'OEB se sont multipliées depuis les années 80 , même si elles ont marqué une pause au début des années 90 . Cette progression, remarquable surtout depuis la fin des années 90, a été plus forte que la croissance moyenne de l'ensemble des demandes déposées auprès de l'OEB.

- Les États-Unis, l'Union européenne et le Japon déposent auprès de l'OEB un nombre sensiblement identique de demandes de brevets sur des nanotechnologies, mais dans le cas des États-Unis et du Japon, celui-ci est relativement plus élevé que le nombre moyen de demandes de brevets que ces pays déposent auprès de l'Office.

- Le secteur de l'enseignement supérieur et le secteur public constituent une source majeure de connaissance dans le domaine des nanotechnologies, et leurs parts dans les demandes de brevets sont beaucoup plus élevées que la moyenne. Depuis le milieu des années 90, ces secteurs jouent un rôle particulièrement important. En raison des différences existant entre les systèmes nationaux, qu'il s'agisse de la science, de la technologie ou de l'innovation, les parts respectives du secteur de l'enseignement supérieur et du secteur public varient selon les pays. Ainsi, la part du secteur public est prédominante en France et au Japon, tandis qu'au Royaume-Uni, aux États-Unis et aux Pays-Bas, le secteur de l'enseignement supérieur représente une part relativement importante. En Allemagne, c'est au secteur privé à but non lucratif que revient la première place.

- Le développement actuel des nanotechnologies dépend essentiellement des technologies appliquées dans les différents pays et des acquis scientifiques qu'ils ont accumulés. Le Japon s'arroge la première place en «électronique», «optoélectronique» et «environnement et énergie», tandis que les États-Unis se classent au premier rang pour « la médecine et les biotechnologies », «les procédés de mesure et de fabrication» et «les nanomatériaux». La part des différents pays en matière de demandes de brevets dans chaque domaine d'application des nanotechnologies est fortement corrélée à leur part respective dans le total des demandes déposées auprès de l'OEB, à l'exception de l'Union européenne. D'autres pays mènent des activités d'invention de plus en plus intenses, en particulier la Corée, qui arrive au quatrième rang pour les nanotechnologies liées à «l'électronique».

\section{Les sciences sont à divers égards le moteur du développement technologique}

- Les sciences concourent de différentes manières aux progrès des nanotechnologies. Une analyse du taux de citation dans les publications autres que les brevets met en évidence l'importance des interactions entre activités scientifiques et activités d'invention dans le secteur des nanotechnologies. On distingue trois types d'interactions. Il existe tout d'abord des activités d'invention directement suscitées par des activités scientifiques. Dans ce cas, au premier stade de leur développement, les technologies concernées représentent une fraction relativement importante des publications hors brevets. Il a ensuite été constaté que certaines technologies sont alimentées en continu par des avancées scientifiques, auquel cas leur part dans les publications hors brevets est relativement 
constante. Enfin, pour certaines technologies, le lien entre science et technologie s'accentue au fil du temps.

- Dans le domaine des nanotechnologies, les activités scientifiques jouent un rôle déterminant dans la création et les flux de connaissances. On a observé que les délais existant entre des inventions successives se sont singulièrement raccourcis en cas de percées scientifiques, comme cela a été le cas avec la découverte des nanotubes de carbone. L'analyse des citations montre que le secteur de l'enseignement supérieur produit un pourcentage relativement élevé des publications de brevets citées fréquemment. 
TABLE OF CONTENTS

CAPTURING NANOTECHNOLOGY'S CURRENT STATE OF DEVELOPMENT VIA ANALYSIS OF

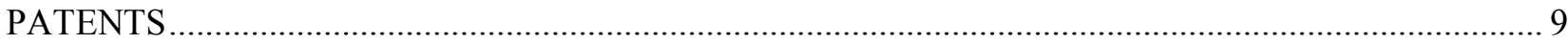

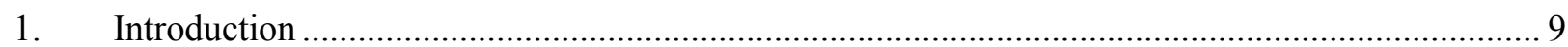

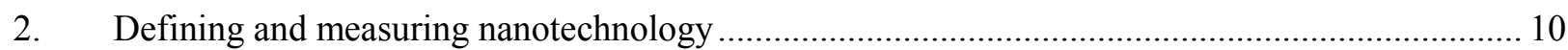

3. Overview of trends in nanotechnology patent applications to EPO ......................................... 12

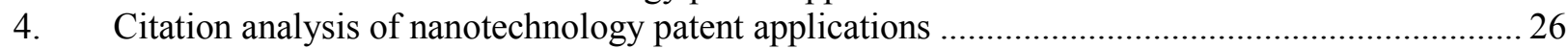

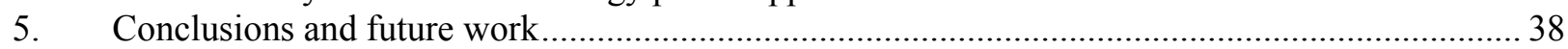

ANNEX A OTHER BASIC STATISTICS IN THE NANOTECHNOLOGY PATENT APPLICATIONS41

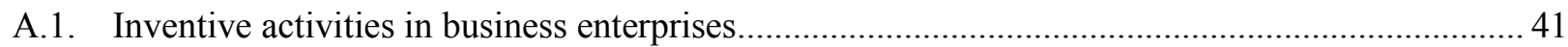

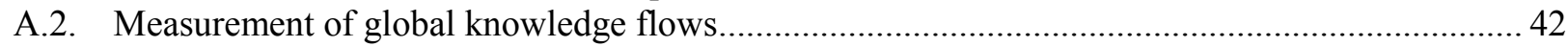

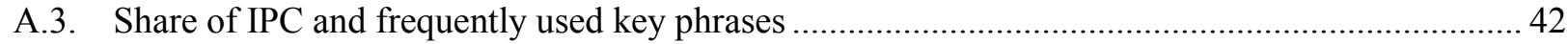

A.4. Trends in patent citations and NPL citations identified via international searches and European searches

45

ANNEX B GLOSSARY OF PATENT TERMINOLOGY AND INDICATORS …................................... 46

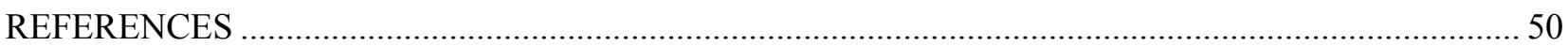


DSTI/DOC(2007)4

\section{CAPTURING NANOTECHNOLOGY'S CURRENT STATE OF DEVELOPMENT VIA ANALYSIS OF PATENTS}

\section{Introduction}

Nanotechnology and nanoscience have been attracting wide recognition in recent years. The specific properties of materials on the nanometre scale are expected to bring significant changes to a wide range of technologies. Because of their potential applications, nanotechnology and nanoscience are considered as one of the promising research fields having important social and economic impacts in the future. Stimulated via the National Nanotechnology Initiative (NNI) launched in the United States in 2000, several countries began to launch new initiatives or prioritise research in nanotechnology.

A wide range of activities is undertaken (Glänzel et al, 2003; Heinze, 2004; Huang et al, 2004; Meyer, 2006a; Meyer, 2006b; Scheu et al, 2006; Zucker et al, 2006) to understand the nature of nanotechnology. Among them, the development of metrics on nanotechnology will be essential to improve our collective understanding of its size, growth and socio-economic impacts. This paper aims at capturing trends in current inventive activities, based on an analysis of nanotechnology-related patents. The analysis addresses questions such as:

- What is the difference between nanotechnology and other conventional technologies? (Particularly in relation to their breadth, sectoral distribution of applicants and international collaboration in invention).

- What is the comparative strength of countries in nanotechnology? (Countries' share in patent applications).

- How do scientific and inventive activities interact in nanotechnology? (Measurement of the ratio of non-patent literature in citations).

- How fast has nanotechnology been evolving over time? (Measurement of time-lags between successive inventions).

A recent study of scientific publications via co-citation analysis identified approximately 30 research areas related to nanoscience and materials and illustrated their multi-disciplinary character (Igami and Saka, 2007). A mapping of science, drawn by using co-citation analysis, clearly showed the emergence of a precursor of nano-bioscience and provided a picture of its evolving nature. The analysis of countries' relative specialisation indexes indicated the substantial and increasing presence of China in nanoscience and materials research.

An analysis solely based on scientific publications, however, is not sufficient to provide an understanding of the socio-economic impacts of scientific discoveries. Relying on patent analysis is likely to be a useful way to examine continuous knowledge flows from science to technology. Patents are, in fact, one of the direct and better measurable outputs of research and development and other inventive activities. 


\section{DSTI/DOC(2007)4}

There has been a long history of describing the structure and evolution of science and technology (Garfield et al, 1964; Small and Sweeney, 1985a; Small et al, 1985b). Recent and unprecedented progress in access to and use of information on scientific publications and patents opens the possibility of innovative ways to study the structure and evolution of science and technology. Among these recent tools, patent-based citation analysis may provide insights into the characteristics of nanotechnology. ${ }^{3}$

By tracing patent citations, threads of technology development could be unveiled (von Wartburg et al, 2005). Citations to prior art contained in nanotechnology patent applications, i.e. backward citations, represent the influence of past inventive activities on nanotechnology patent applications. The ratio of nonpatent literature in backward citations is a proxy for measuring linkages between scientific and inventive activities (Narin et al, 1997; Harhoff 2003; Meyer, 2006a). Knowledge spillovers between inventors or geographic regions have also been studied in the literature (Jaffe and Trajtenberg, 1998, Jaffe et al, 2000). Time-lags between nanotechnology patent applications and prior art show technological paths and dependencies that have an influence on nanotechnology inventive activity. Sudden changes in time-lags would indicate the existence of technological breakthroughs or changes in technological trends. Counts of citations to nanotechnology patent applications from other patent applications, i.e. forward citations, are considered as indicators of the economic or technological value of patents (Lanjouw and Schankerman, 1999; Harhoff et al, 1999; 2003; Henderson et al, 1998; Jaffe et al, 2000).

This paper is organised as follows: Section 2 briefly explains the definition and data used in the analysis; Section 3 provides an overview of trends in nanotechnology patent applications to the European Patent Office (EPO), as well as countries' and sectors' shares in the nanotechnology patent applications; Section 4 analyses citations and shows indicators for measuring linkages between scientific and inventive activities, and time-lags between successive inventions; Section 5 concludes and draws some proposals for future work. Finally, Annex A provides other basic statistics on the nanotechnology patent applications and Annex B gives a glossary of patent terminology and indicators.

\section{Defining and measuring nanotechnology}

\subsection{Definition of nanotechnology}

As of today, there is no single definition of nanotechnology. History shows that some scientists already envisaged the possibility for science and technology to evolve on a nanometre scale at the end of the 1950s. Renowned physicist Richard Feynman addressed the possibility of manufacturing atom by atom in his famous talk in 1959 (Feynman, 1959). Ryogo Kubo, a physicist famous for statistical physics and non-equilibrium statistical mechanics, pointed out peculiar properties in metal particles on the nanometre scale (Kubo, 1962). It took a long time for these early predictions to become reality, mainly because of the lack of measuring and manufacturing techniques. Successive scientific and technological breakthroughs such as the realisation of quantum wires and dots, the invention of scanning tunnelling microscopy (Binning et al, 1982) and atomic force microscopy (Binning et al, 1986), and the discoveries of fullerenes (Kroto et al, 1985) and carbon nanotubes (Iijima, 1991) have contributed to the development of science and technology on the nanometre scale.

A turning point in science and technology policy in relation to nanotechnology is the launch of the NNI in the United States in 2000. Since then, major countries have begun to launch initiatives or prioritise research in nanotechnology. Table 1 shows definitions of nanotechnology in the NNI, the $7^{\text {th }}$ Framework Programme in the European Union, and the Second Science and Technology Basic Plan in Japan. While definitions may vary by country, they also have some common elements: $i$ ) the scale of length, ii) the

3. There are many different characteristics that can be analysed drawing on scientific and patent citations. An extensive comparison between scientific and patent citations can be found in Meyer M. (2000). 
uniqueness and peculiarity of phenomena on the nanometre scale, and iii) its potential application to a wide range of science and technology. It is also commonly noted that nanotechnology targets phenomena on the nanometre scale as well as apparatuses to control and measure the phenomena.

This paper analysed nanotechnology patent applications identified via the EPO (Scheu et al, 2006). The definition of nanotechnology in the EPO is the following:

The term nanotechnology covers entities with a controlled geometrical size of at least one functional component below 100nm in one or more dimensions susceptible to make physical, chemical or biological effects available which are intrinsic to that size. It covers equipment and methods for controlled analysis, manipulation, processing, fabrication or measurement with a precision below $100 \mathrm{~nm}$.

The definition is consistent with other definitions. It describes the scale of length, the phenomena intrinsic to the size, the involvement of a wide range of technologies, and the inclusion of equipment and methods. An additional point raised in this definition is the description of dimensionality. Other definitions do not mention this aspect, but this does not bring major changes to the definition. It is well known that spatial confinement of electrons or atoms along with one or two dimensional directions, like quantum wires and carbon nanotubes, is enough to observe peculiar and intrinsic phenomena on the nanometre scale.

\section{Table 1. Some definitions of nanotechnology}

\begin{tabular}{ll}
\hline \multicolumn{1}{c}{ Source } & Definition \\
\hline \hline & Nanotechnology is the understanding and control of matter at dimensions of roughly \\
National & 1 to 100 nanometers, where unique phenomena enable novel applications. Encompassing nanoscale \\
Nanotechnology & science, engineering and technology, nanotechnology involves imaging, measuring, modeling, and \\
Initiative (2001-) & manipulating matter at this length scale.
\end{tabular}

Generating new knowledge on interface and size-dependent phenomena; nano-scale control of material properties for new applications; integration of technologies at the nano-scale; self-assembling 7th Framework properties; nano-motors; machines and systems; methods and tools for characterisation and Programme (2007-) manipulation at nano dimensions; nano precision technologies in chemistry for the manufacture of basic materials and components; impact on human safety, health and the environment; metrology, monitoring and sensing, nomenclature and standards; exploration of new concepts and approaches for sectoral applications, including the integration and convergence of emerging technologies.

Second Science and Technology Basic Plan (2001-2005)
Nanotechnology is an interdisciplinary S\&T that encompasses IT technology, the environmental sciences, life sciences, materials science, etc. It is for controlling and handling atoms and molecules in the order of nano $(1 / 1000000000)$ meter enabling discovery of new functions by taking advantage of its material characteristics unique to nano size, so that it can bring technological innovation in various fields.

Source: National Nanotechnology Initiative: http://www.nano.gov; 7th Framework Program: http://cordis.europa.eu/fp7/home.html; Science and Technology Basic Plan: http://www8.cao.go.jp/cstp/english/basic/index.html.

\subsection{Nanotechnology patents at EPO}

Reflecting the increasing interest and importance of nanotechnology in patents, three major patent offices, namely the United States Patent and Trademark Office (USPTO), the EPO, and the Japan Patent Office (JPO), have made intense efforts to improve their own respective classification systems and collect all nanotechnology-related patents in one single patent class:

- $\quad$ The USPTO created a cross-reference-art collection class, class 977. 
- $\quad$ The EPO created Y01N.

- $\quad$ The JPO created ZNM.

The identification of nanotechnology patents requires elaborate work. In the EPO case (Scheu et al, 2006), a nanotechnology working group (NTWG) was created in 2003. At first, the NTWG worked on the definition of nanotechnology, referred to in section 2.1, for watching trends in nanotechnology patents. After that, the NTWG identified nanotechnology patents through keyword searches, consultations with nanotechnology experts in the EPO, and peer reviews by external experts. Patent applications from 15 countries or organisations ${ }^{4}$ were analysed. As a consequence of these endeavours, about 90000 patent or non patent literature documents out of 20 million documents were tagged to class Y01N.

The Y01N tag is based on the combined effort of many examiners from different technical fields. It is a reliable classification of nanotechnology patent applications, even though some limitations in the tagging were pointed out (Scheu et al, 2006). The tagging system partly relies on ad hoc assignment by classifiers; therefore some nanotechnology patents might be missed. Furthermore, the tags are not suitable for exploring new emerging technologies that have not been widely recognised yet.

\section{3. $\quad$ OECD/EPO patent citations database}

Among nanotechnology patent applications published by various patent authorities, patent applications to the EPO (direct or filed via the Patent Cooperation Treaty (PCT)) were intensively analysed. The OECD/EPO patent citations database was used in this analysis (Webb et al, 2005). A notable feature of the database is its inclusion of citation information. The citation information opens a way to a variety of analyses such as forward and backward citation analyses. These techniques are recognised as useful and effective tools for exploring trajectories of technological development and the influence of technologies on successive inventive activities (von Wartburg et al, 2005 and references therein). The database also includes information on citations to non-patent literature (NPL). Measurement of the ratio of NPL in citations will shed light on the linkages between scientific and inventive activities. Based on data availability in the OECD/EPO patent citations database, the analysis covers the period 1978-2005.

Being based on patent applications filed at the EPO, the analysis may underestimate innovative activities in non-European countries, especially in the United States and Asian countries. Furthermore, it should be noted that not all inventions are being patented (Arundel and Kabla, 1998). Nevertheless, measuring the extent of protection sought in the European market by non-European applicants can reveal their intellectual property rights strategies in the nanotechnology area.

\section{Overview of trends in nanotechnology patent applications to EPO}

\subsection{Analysis on countries' share in the nanotechnology patent applications}

Inventive activities in nanotechnology have been gathering momentum since the end of the 1990s. Figure 1 shows trends in nanotechnology patent applications to the EPO (direct or via PCT) from 1984 to 2002, along with the growth rates of nanotechnology patent applications and the overall EPO number of applications. The number of nanotechnology patent applications to the EPO increased from the mid-1980s to the early 1990s. After that, the trend slowed down and the number of applications did not change significantly until the mid-1990s. These trends are consistent with those of overall EPO applications. The

4. They are: African Intellectual Property Organisation, African Regional Intellectual Property Organisation, Austria, Australia, Belgium, Canada, Switzerland, Germany, EPO, France, United Kingdom, Luxembourg, Netherlands, United States and World Intellectual Property Organization. 
number of applications began to surge again after the mid-1990s and shows a remarkable increase in the past 10 years. The growth rate in nanotechnology patent applications surpassed that of overall EPO applications from 1996. The average annual growth rate from 1996 to 2002 is approximately $15 \%$. Analysis of patents in the USPTO shows a similar remarkable increase in nanotechnology patents from the mid-1990s (Huang et al, 2004).

Figure 1. Trends in nanotechnology patent applications to the EPO (direct or via PCT)

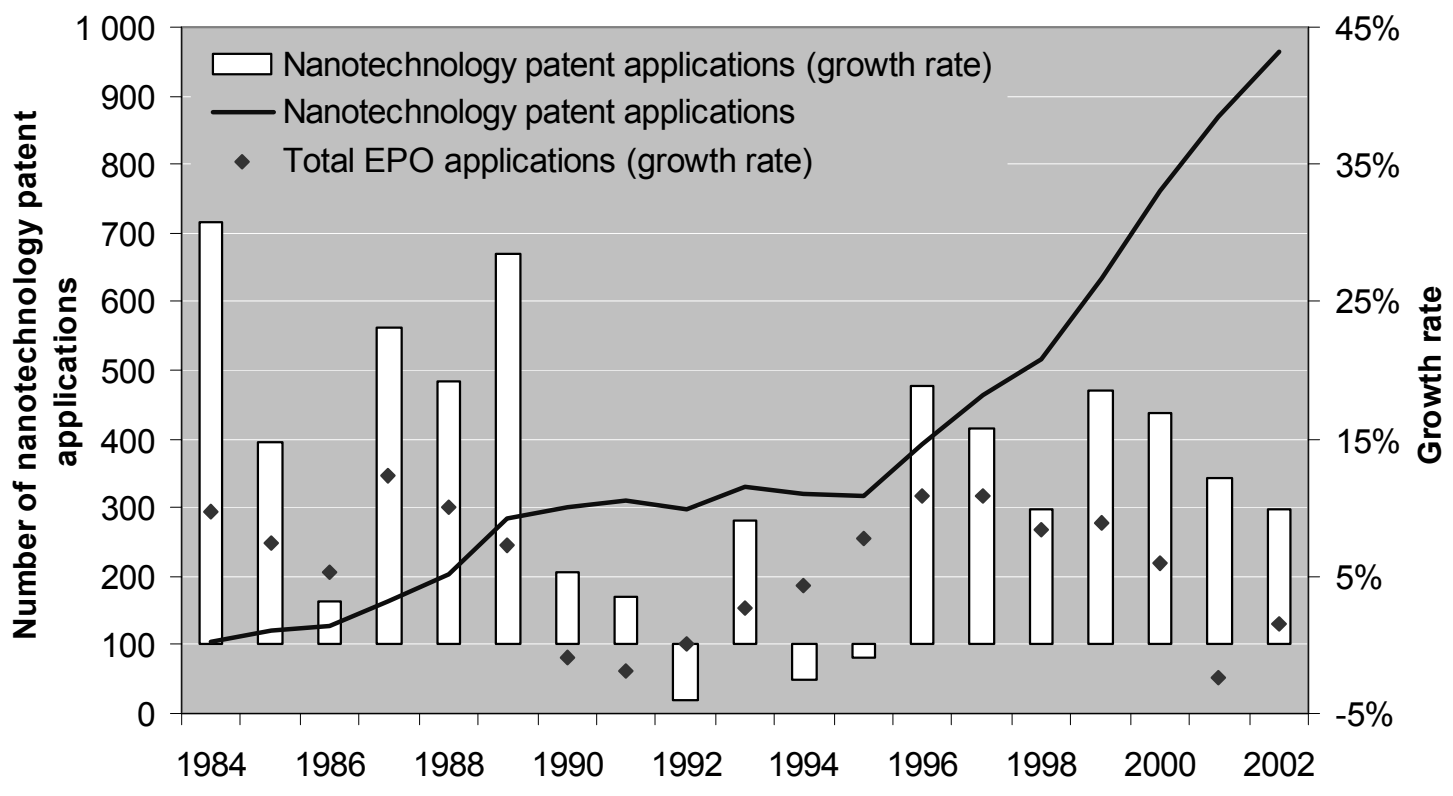

Note: Patent counts are based on the earliest priority date and fractional counts.

Source: OECD, Patent Database, September 2006, based on a list of patents selected by the EPO.

The US and Japanese shares are notably larger than their shares in overall EPO applications. Figure 2 shows countries' shares in nanotechnology patent applications from 1978 to 2005. The United States accounts for about one third of nanotechnology patent applications, followed closely by Japan and the European Union. Germany, France and the United Kingdom are the leading countries in the European Union. Among the remaining countries, Korea, Switzerland and Canada hold the largest shares.

Figure 3 shows countries' shares in nanotechnology patent applications to the EPO in the periods 1995-1997 and 2000-2002. The graph covers OECD countries and Brazil, China, Chinese Taipei, India, Israel, Singapore, South Africa, Russian Federation. The analysis of nanotechnology patent applications so far does not show the increase in Chinese applications. Several analyses based on scientific publications documented the emergence of Brazil, Russia, India, and China (BRIC). Especially, the increasingly vital role of China in knowledge creation in nanoscience was observed (Zhou and Leydesdorff, 2006; Igami and Saka, 2007). There seems to be some time-lags between the act of invention and the creation and diffusion of scientific knowledge as reflected in scientific publications. 


\section{DSTI/DOC(2007)4}

Figure 2. Countries' shares in nanotechnology patent applications to the EPO (1978 - 2005)

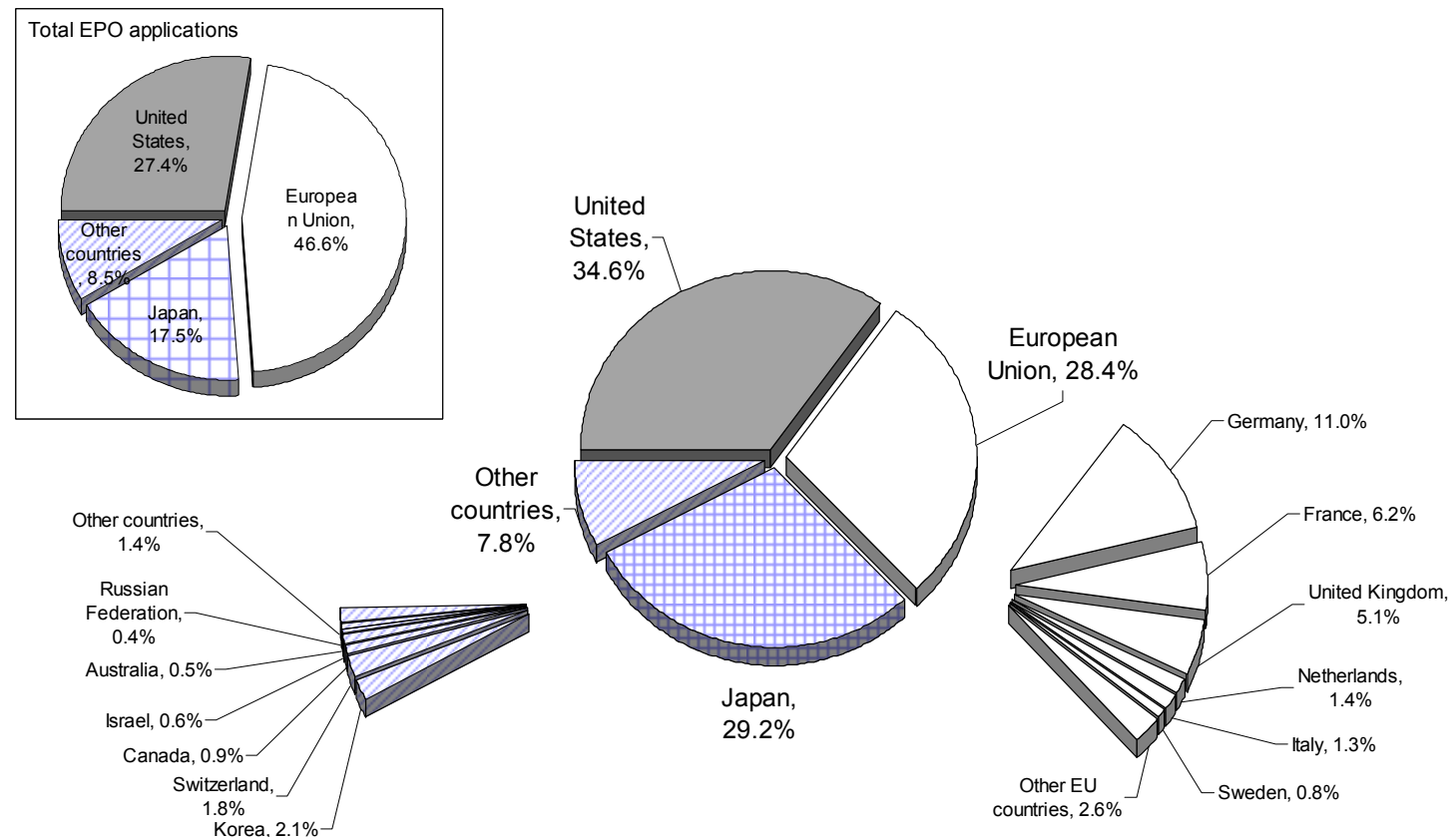

Note: Patent counts are based on the earliest priority date, the inventor's country of residence, and fractional counts.

Source: OECD, Patent Database, September 2006, based on a list of patents selected by the EPO.

Figure 3. Countries' shares in nanotechnology patent applications to the EPO (1995-1997 and 2000-2002)

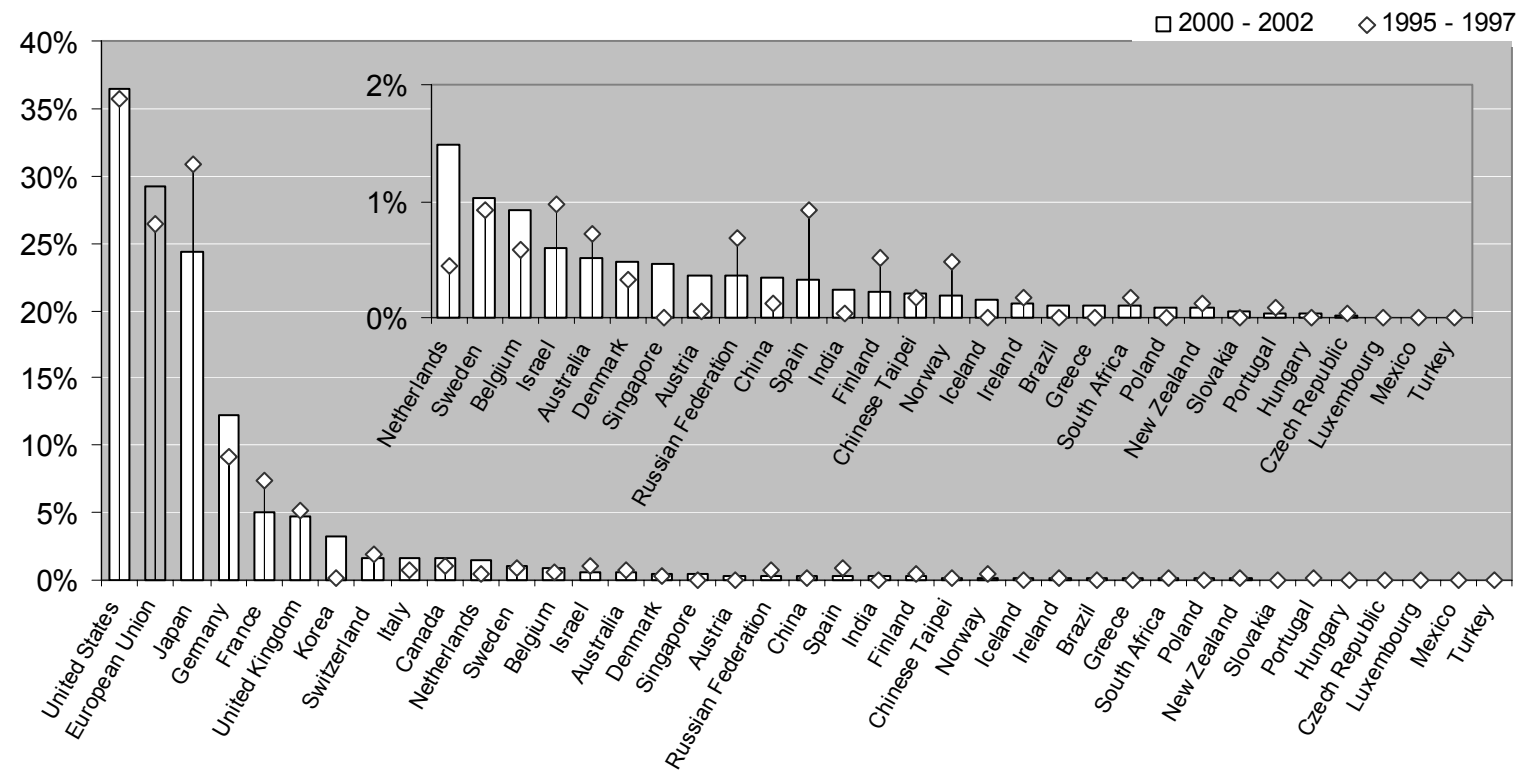

Note 1: Patent counts are based on the earliest priority date, the inventor's country of residence, and fractional counts.

Note 2: The graph covers OECD countries and Brazil, China, Chinese Taipei, India, Israel, Singapore, South Africa, Russian Federation.

Source: OECD, Patent Database, September 2006, based on a list of patents selected by the EPO. 
Trends in nanotechnology patent applications from the major economies and leading patenting countries are shown in Figure 4. The number of nanotechnology patent applications from the United States and the European Union registered an average annual increase of 12\% between 1986 and 1996. In 1997, the average annual growth rate increased to about $18 \%$ for the US and $19 \%$ for the EU applications. The sharp surge in the EU numbers is mainly due to substantial growth in Germany's applications. The annual number of applications from Germany jumped from about 40 in the mid-1990s to over 100 in 2001.

Nanotechnology patent applications from Japan also showed a steady increase until the end of the 1980s, followed by a decline of about $6 \%$ per year between 1990 and 1994 . That period corresponds to the collapse of the Japanese asset price bubble. Japan seems to experience a loss of technological knowledge in this period. This is one of the reasons why the total number of nanotechnology patent applications remained constant from early to mid-1990s. An uptake in nanotechnology patent applications from Japan was registered as from 1995, but the annual growth rate, at $12 \%$, remains smaller than that of US and EU applications.

The share of other countries has been increasing notably since the mid-1990s. Among the leading countries, Korea shows a remarkable increase since 1997. The average annual growth rate from 1999 to 2001 is approximately $40 \%$. A notable increase in patent applications from Korea is also registered in patents filed to the USPTO (Huang et al, 2004).

Trends in the shares of nanotechnology patent applications for the United States, the European Union, Japan and other countries are shown in Figure 4(d). The United States has the largest share from 1979 to 1985. Japan replaced the United States in this position from the mid-1990s to the end of 1990s. After a sharp decrease at the beginning of the 1990s, Japan's share has been steadily decreasing, because of the relatively faster growth of other countries' applications. As a consequence, the United States had the largest share in 2001, followed by the European Union and Japan. The share of other countries has been increasing steadily in the past decade and it accounts for about $10 \%$ of nanotechnology patent applications in 2001 . 
Figure 4. Trends in nanotechnology patent applications to the EPO. The number of applications from major countries (a) - (c) and their share (d)

(a)

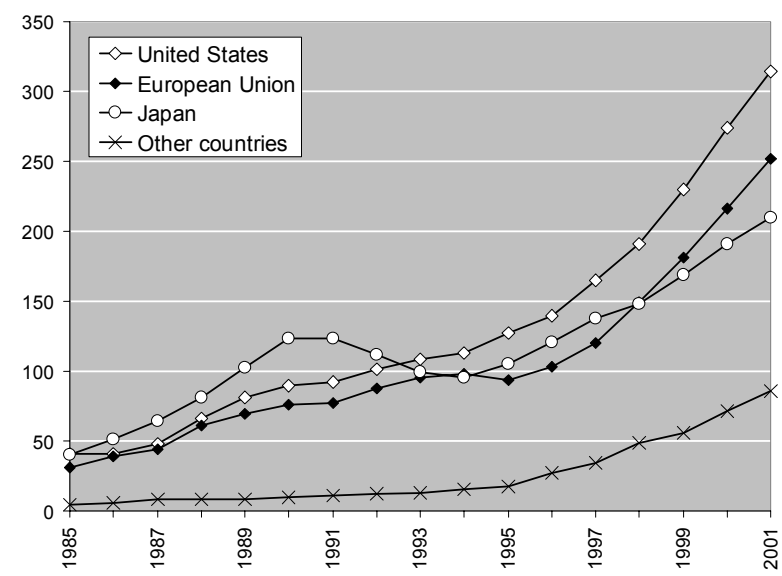

(c)

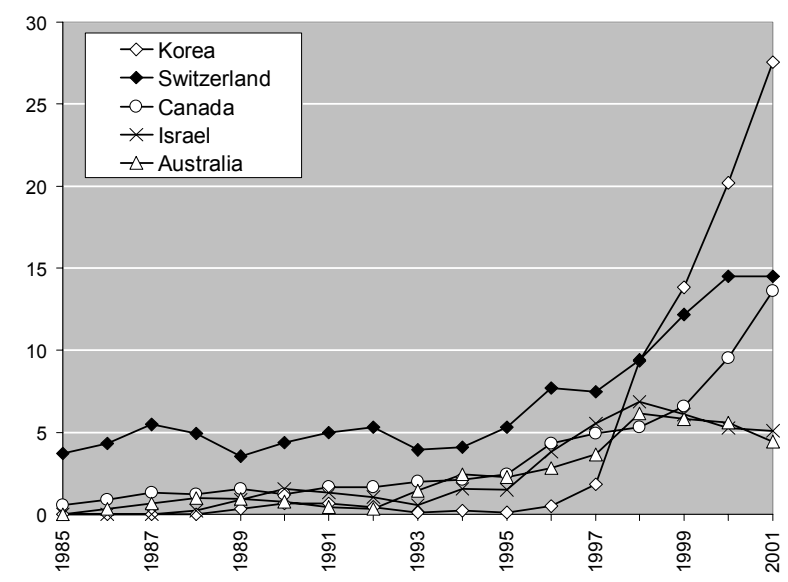

(b)

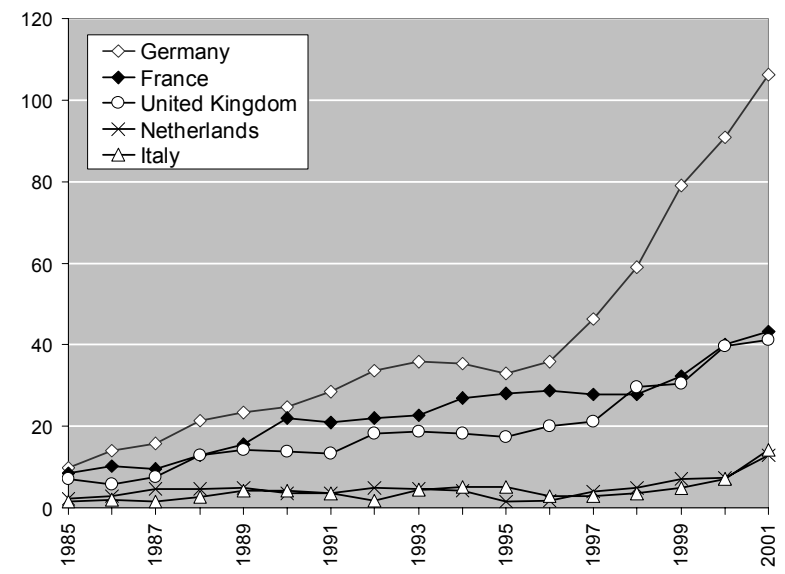

(d)

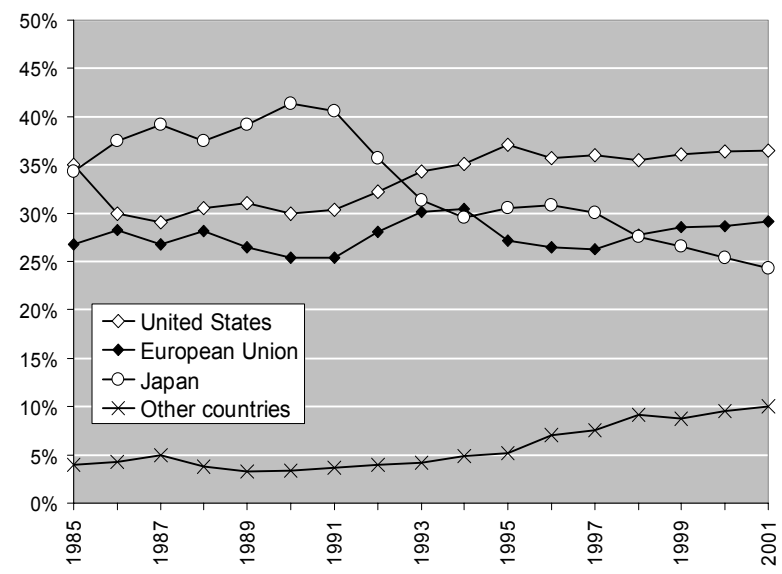

Note: Patent counts are based on the earliest priority date, the inventor's country of residence, and fractional counts. Figures show three years' moving averages.

Source: OECD, Patent Database, September 2006, based on a list of patents selected by the EPO. 


\subsection{Sector analysis of nanotechnology patent applications}

Higher education and government sectors are an important source of knowledge in nanotechnology. Figures 5 and 6 show the shares of different sectors, i.e. business enterprise, government, individuals, private non-profit, and higher education, in nanotechnology patent applications. The results presented here are based on analysis of applicants. The business enterprise sector accounts for about $80 \%$ of nanotechnology patent applications, which is approximately $10 \%$ lower than its share in overall EPO applications in the same period, as shown in Figure 5(a). This is because of the larger shares of the government $(5 \%)$ and higher education $(8 \%)$ sectors. These results are consistent with other studies (Heinze, 2004; Meyer, 2006a). The contributions of the government and higher education sectors have been important since the mid-1990s, as shown in Figure 6(a). These trends suggest that there has been some kind of qualitative change in nanotechnology research itself or in science, technology, and innovation policy, such as prioritisation of nanotechnology or active promotion of co-operation among industry, academia, and government.

The sectoral distribution in EPO nanotechnology patent applications varies across countries. The business enterprise sector accounted for approximately $73 \%$ of applications from the United States in 2000-2002. This figure is roughly $17 \%$ smaller than the share of business enterprise in overall EPO applications in the same period (OECD, 2006). The higher education sector holds a share of about $18 \%$, which is also higher than the share in total EPO applications (less than 5\%). The share of the higher education sector had been increasing since the early 1990s and reached about $20 \%$ in 1999 . The ratio slightly decreased after 1999 and was about 17\% in 2001.

The contribution of government and higher education to nanotechnology patenting activity in the European Union has also been gradually increasing since the early 1990s. It reached about $15 \%$ in 2001. Because of differences in national science, technology, and innovation systems, sector shares vary across countries in the European Union. Figure 5 shows the shares of five sectors in the five leading European Union countries. The government share is notably large in France. It accounts for about $25 \%$ of all nanotechnology applications. In contrast, the higher education sector holds a $17 \%$ share in the United Kingdom. The share of private non-profit reaches $12 \%$ in Germany.

In Japan, business enterprise dominated patent applications until the middle of 1990s. After enjoying a sharp surge in applications, the number of applications decreased from 1991 to 1995. Stagnation of the nanotechnology patent applications, observed in Figure 1, is attributable to decreasing patent applications from Japanese business enterprises. Patent applications from Japanese business enterprises recovered from 1995. Along with this recovery, patent applications from the government sector show a remarkable increase. The government sector accounted for $11 \%$ of nanotechnology patent applications in 2001 . The ratio is five times larger than the ratio in 1995.

It should be noted that in certain countries, like Sweden and until recently Germany and Japan, university professors are entitled to own patents resulting from their research. As a consequence, these patent applications are not registered as belonging to public institutions. However, in many cases, except for other countries in Figure 6(e), patent applications owned by individuals remain small and almost constant, indicating that this difference in the legal framework does not have a serious influence on the results presented here. 


\section{DSTI/DOC(2007)4}

Figure 5. Countries' shares in nanotechnology patent applications to the EPO owned by (a) Business enterprise, (b) Government, (c) Higher education sectors, and (d) Private non-profit (1978-2005)

(a) Business enterprise

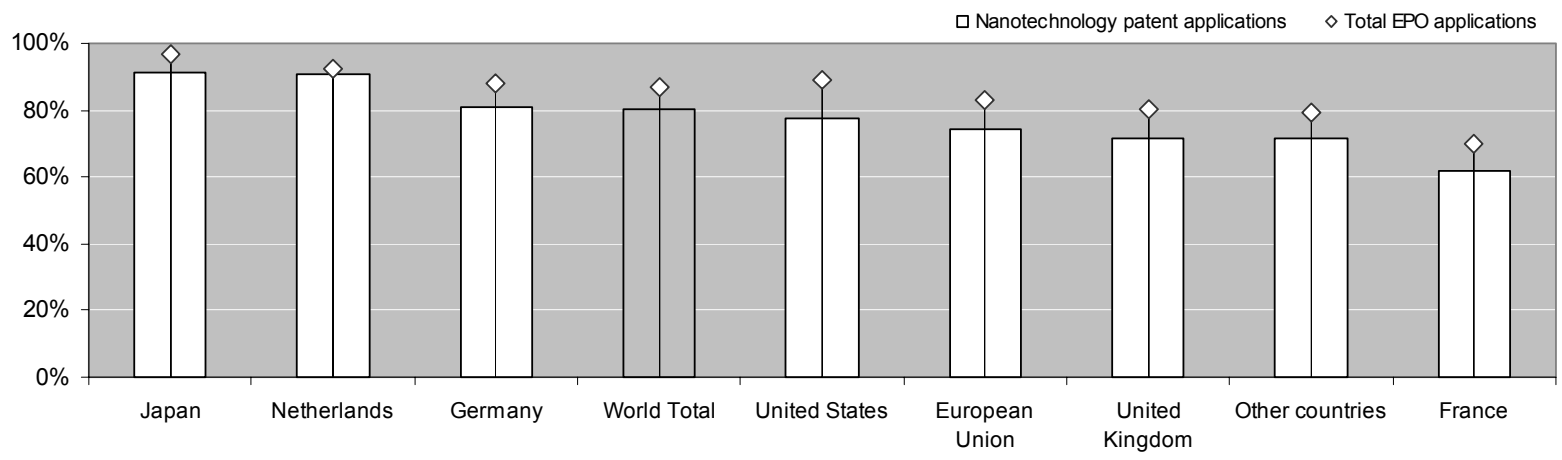

(b) Government

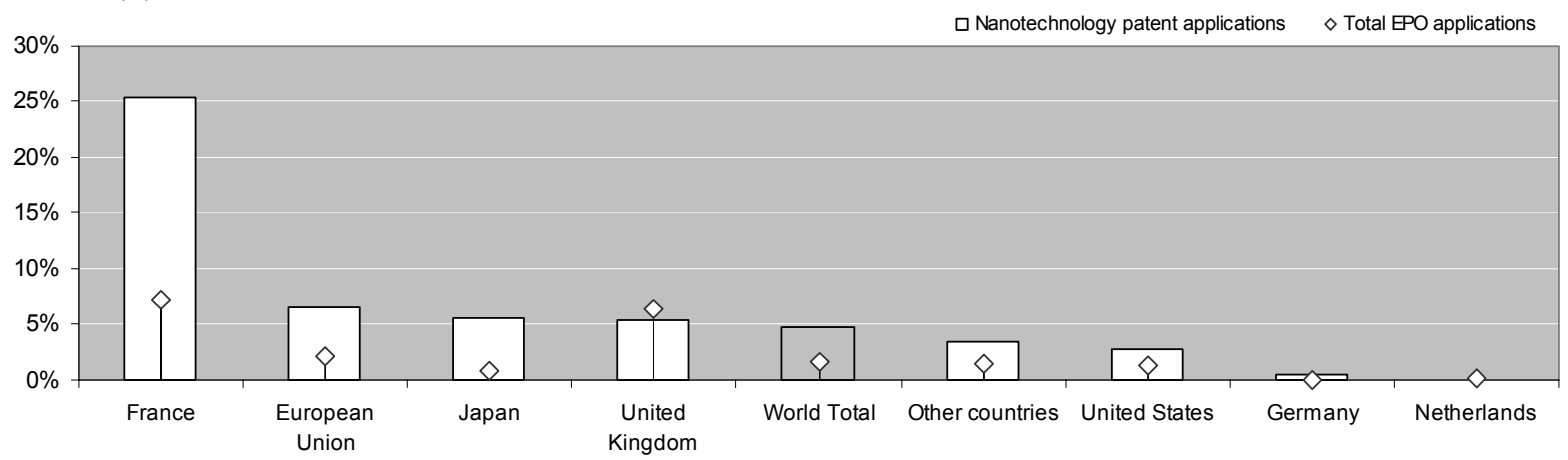

(c) Higher education

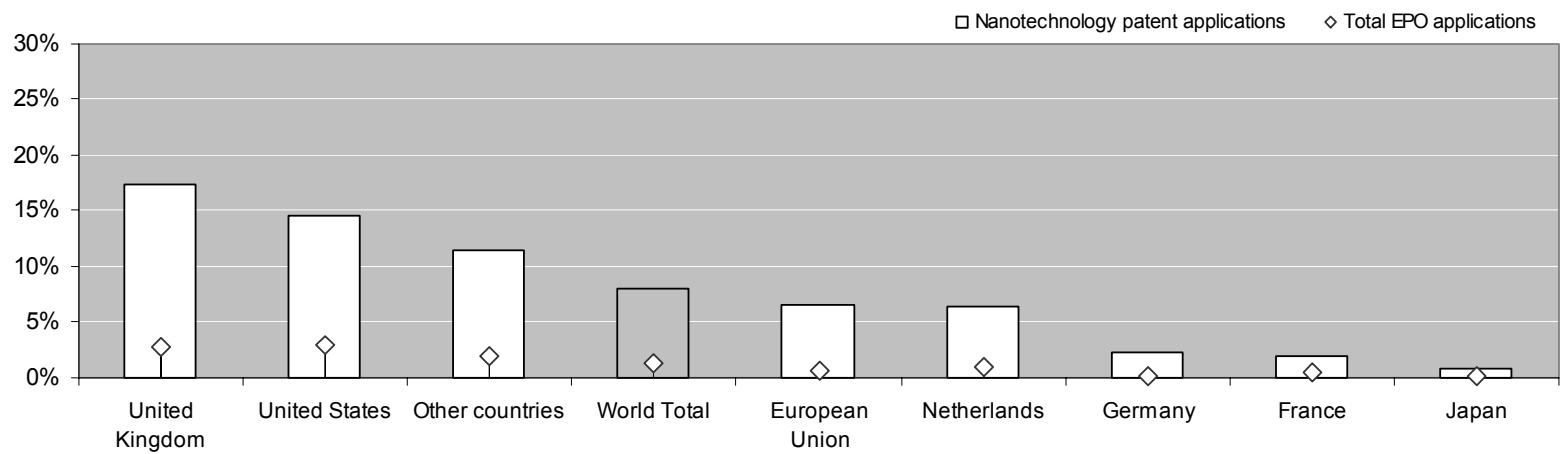

(d) Private non-profit

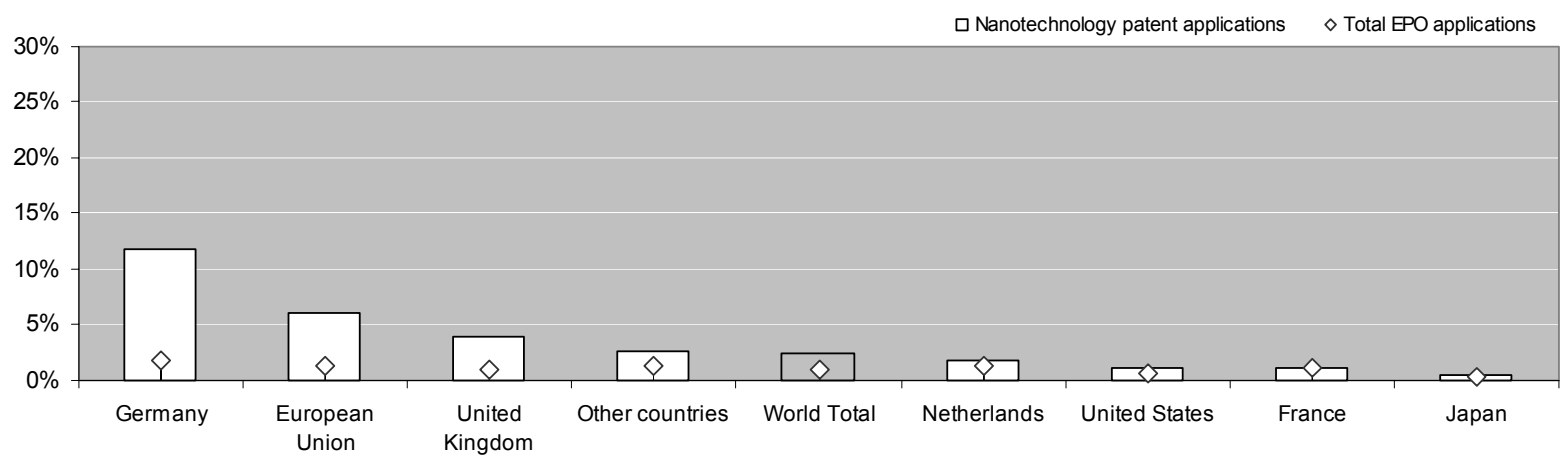

Note: Patent counts are based on the applicant's sector and country of residence and fractional counts.

Source: OECD, Patent Database, September 2006, based on a list of patents selected by the EPO. Sector classifications are based on the Eurostat sector attribution algorithm. 
Figure 6. Trends in sectors' share in nanotechnology patent applications to the EPO in (a) total nanotechnology patent applications, (b) United States,

(c) European Union, (d) Japan, and (e) other countries

(a) Total nanotechnology patent applications

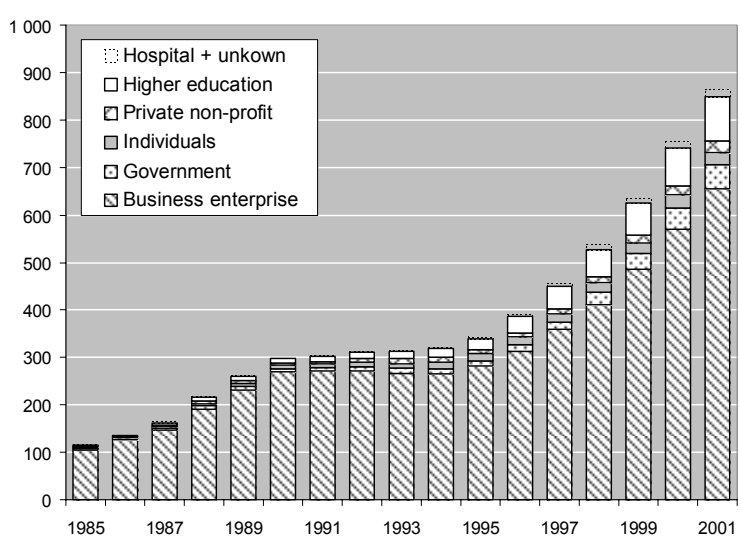

(b) United States

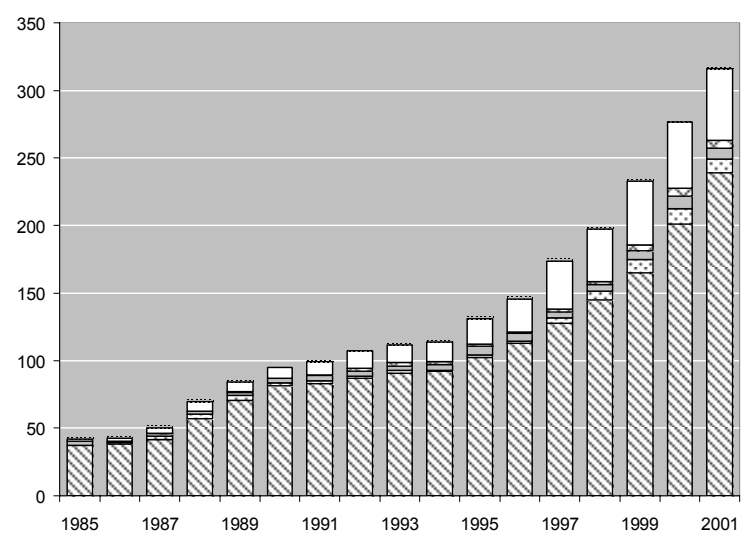

(d) Japan

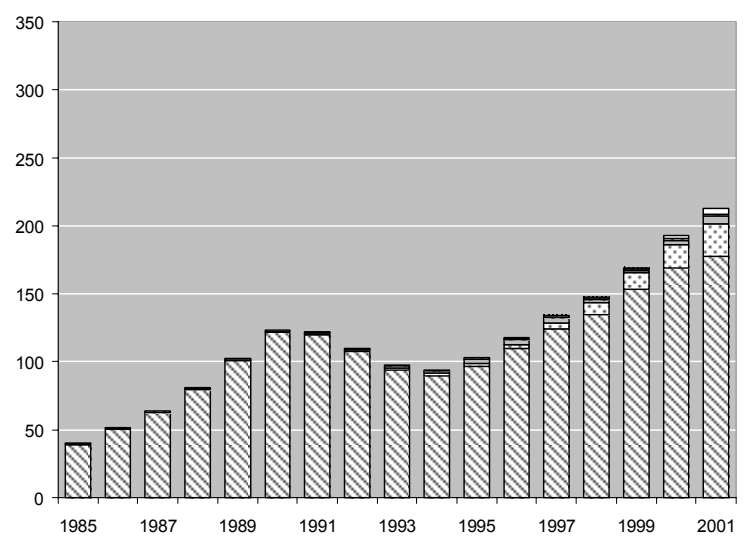

(c) European Union

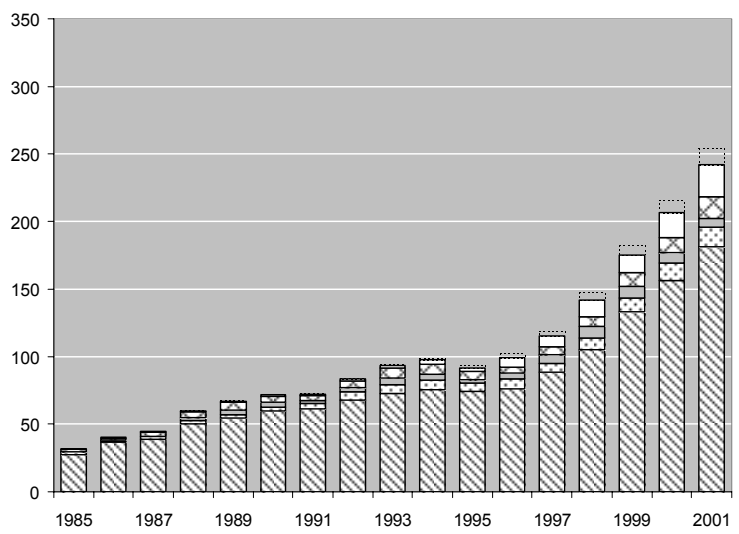

(e) Other countries

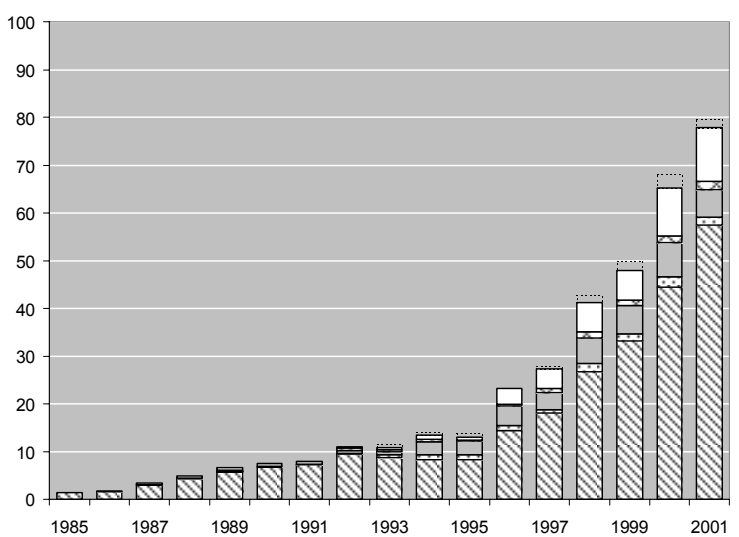

Note: Patent counts are based on the earliest priority date, the applicant's sector and country of residence, and fractional counts. Figures show three years' moving averages.

Source: OECD, Patent Database, September 2006, based on a list of patents selected by the EPO. Sector classifications are based on the Eurostat sector attribution algorithm. 


\section{3. $\quad$ Trends in nanotechnology patent applications by application fields}

Because of the peculiar properties of materials on the nanometre scale, nanotechnology is believed to underpin a wide range of technologies. In order to analyse the breadth of its applications, nanotechnology patent applications are further categorised into six application fields based on the International Patent Classification (IPC). The six application fields and their IPC are shown in Table 2. ${ }^{5}$ According to a key phrase analysis (see Appendix A.3), it is found that each field consists of technologies such as:

- Electronics: semiconductor memories, magnetic random access memories, flat panel display devices, quantum information processing, and molecular devices.

- Optoelectronics: lasers, photonic crystals, optical devices, optical waveguides.

- Medicine and biotechnology: drug deliveries, molecular detection method, and high resolution DNA detection method, applications of $\mathrm{TiO}_{2}$ to sun screening.

- Measurements and manufacturing: matrix screening methods, scanning probe microscope, and polymer processing method.

- Environment and energy: fuel cell electrode, non-aqueous electrolyte secondary cell, and lithium secondary cell.

- Nano materials: carbon nanotubes, organic nanotubes, nano-whisker, and oxide particles.

The key phrase analysis shows that the majority of technologies in the six application fields, except for "Nano materials", are achieved via the top-down process $^{6}$, where nano-structures are developed through the improvement or advancement of existing miniaturisation technologies such as lithography technologies. In contrast, "Nano materials" are synthesised through the bottom-up process, where nano-structures are organised through chemical or physical interactions among atoms or molecules.

The increase in patent applications of bottom-up nanotechnologies in the past decade is likely to be one of the driving forces leading to the acceleration of inventive activities in nanotechnology. Figure 7 shows trends in nanotechnology patent applications by fields. Each field has substantial patent applications except for "Environment and energy". The increase in patent applications is especially remarkable in "Nano materials," it has the largest share in 2002 among six application fields.

5. The identification of the categories is subjective. For example, the EPO further classified Y01N tags into six sub-codes (Scheu 2006). The analysis on linkages between patent applications will provide a comprehensive view on the classification and mutual interaction among technologies.

6. Phrases in "bold" in the key phrases show typical bottom-up nanotechnologies. Nanotechnologies in which nano-structures are organised through chemical or physical interactions among atoms or molecules are selected. 
DSTI/DOC(2007)4

Table 2. Six application fields and their IPC

\begin{tabular}{|c|c|c|}
\hline Field name & IPC & Definition in IPC (8th edition) \\
\hline \multirow{4}{*}{ Electronics } & "H01L & SEMICONDUCTOR DEVICES; ELECTRIC SOLID STATE DEVICES NOT OTHERWISE PROVIDED FOR \\
\hline & $\mathrm{H} 01 \mathrm{~J}$ & ELECTRIC DISCHARGE TUBES OR DISCHARGE LAMPS \\
\hline & G06N & COMPUTER SYSTEMS BASED ON SPECIFIC COMPUTATIONAL MODELS \\
\hline & G11 & INFORMATION STORAGE \\
\hline \multirow{2}{*}{ Optoelectronics } & G02 & OPTICS \\
\hline & $\mathrm{H} 01 \mathrm{~S}$ & DEVICES USING STIMULATED EMISSION \\
\hline \multirow[b]{2}{*}{ Medicine and biotechnology } & A61 & MEDICAL OR VETERINARY SCIENCE; HYGIENE \\
\hline & C12 & $\begin{array}{l}\text { BIOCHEMISTRY; BEER; SPIRITS; WINE; VINEGAR; MICROBIOLOGY; ENZYMOLOGY; MUTATION OR GENETIC } \\
\text { ENGINEERING }\end{array}$ \\
\hline \multirow{5}{*}{$\begin{array}{l}\text { Measurements and } \\
\text { manufacturing }\end{array}$} & G01 & MEASURING; TESTING \\
\hline & B01 & PHYSICAL OR CHEMICAL PROCESSES OR APPARATUS IN GENERAL \\
\hline & B21 & MECHANICAL METAL-WORKING WITHOUT ESSENTIALLY REMOVING MATERIAL; PUNCHING METAL \\
\hline & B23 & MACHINE TOOLS; METAL-WORKING NOT OTHERWISE PROVIDED FOR \\
\hline & B32B & $\begin{array}{l}\text { LAYERED PRODUCTS, i.e. PRODUCTS BUILT-UP OF STRATA OF FLAT OR NON-FLAT, e.g. CELLULAR OR } \\
\text { HONEYCOMB, FORM }\end{array}$ \\
\hline \multirow[b]{2}{*}{ Environment and energy } & $\mathrm{CO} 2 \mathrm{~F}$ & TREATMENT OF WATER, WASTE WATER, SEWAGE, OR SLUDGE \\
\hline & $\mathrm{H} 01 \mathrm{M}$ & $\begin{array}{l}\text { PROCESSES OR MEANS, e.g. BATTERIES, FOR THE DIRECT CONVERSION OF CHEMICAL ENERGY INTO } \\
\text { ELECTRICAL ENERGY }\end{array}$ \\
\hline \multirow{14}{*}{ Nano materials } & B01J & CHEMICAL OR PHYSICAL PROCESSES, e.g. CATALYSIS, COLLOID CHEMISTRY; THEIR RELEVANT APPARATUS \\
\hline & B81B & MICRO-STRUCTURAL DEVICES OR SYSTEMS, e.g. MICRO-MECHANICAL DEVICES \\
\hline & B82B & NANO-STRUCTURES; MANUFACTURE OR TREATMENT THEREOF \\
\hline & C01B & NON-METALLIC ELEMENTS; COMPOUNDS THEREOF \\
\hline & C01G & COMPOUNDS CONTAINING METALS NOT COVERED BY SUBCLASSES C01D OR C01F \\
\hline & C03B & MANUFACTURE, SHAPING, OR SUPPLEMENTARY PROCESSES \\
\hline & $\mathrm{CO3C}$ & $\begin{array}{l}\text { CHEMICAL COMPOSITION OF GLASSES, GLAZES, OR VITREOUS ENAMELS; SURFACE TREATMENT OF GLASS; } \\
\text { SURFACE TREATMENT OF FIBRES OR FILAMENTS FROM GLASS, MINERALS OR SLAGS; JOINING GLASS TO } \\
\text { GLASS OR OTHER MATERIALS }\end{array}$ \\
\hline & $\mathrm{C} 04$ & CEMENTS; CONCRETE; ARTIFICIAL STONE; CERAMICS; REFRACTORIES \\
\hline & $\mathrm{C} 07$ & ORGANIC CHEMISTRY \\
\hline & $\mathrm{C08}$ & $\begin{array}{l}\text { ORGANIC MACROMOLECULAR COMPOUNDS; THEIR PREPARATION OR CHEMICAL WORKING-UP; } \\
\text { COMPOSITIONS BASED THEREON }\end{array}$ \\
\hline & C09 & $\begin{array}{l}\text { DYES; PAINTS; POLISHES; NATURAL RESINS; ADHESIVES; COMPOSITIONS NOT OTHERWISE PROVIDED FOR; } \\
\text { APPLICATIONS OF MATERIALS NOT OTHERWISE PROVIDED FOR }\end{array}$ \\
\hline & $\mathrm{C} 22$ & METALLURGY; FERROUS OR NON-FERROUS ALLOYS; TREATMENT OF ALLOYS OR NON-FERROUS METALS \\
\hline & $\mathrm{C} 23 \mathrm{C}$ & $\begin{array}{l}\text { COATING METALLIC MATERIAL; COATING MATERIAL WITH METALLIC MATERIAL; CHEMICAL SURFACE } \\
\text { TREATMENT; DIFFUSION TREATMENT OF METALLIC MATERIAL; COATING BY VACUUM EVAPORATION, BY } \\
\text { SPUTTERING, BY ION IMPLANTATION OR BY CHEMICAL VAPOUR DEPOSITION, IN GENERAL; INHIBITING } \\
\text { CORROSION OF METALLIC MATERIAL OR INCRUSTATION IN GENERAL }\end{array}$ \\
\hline & $\mathrm{C} 30$ & CRYSTAL GROWTH \\
\hline
\end{tabular}

Source: Based on the classification in Nanotechnology Researchers Network Centre, Japan.

Figure 7. Trends in nanotechnology patent applications by application fields

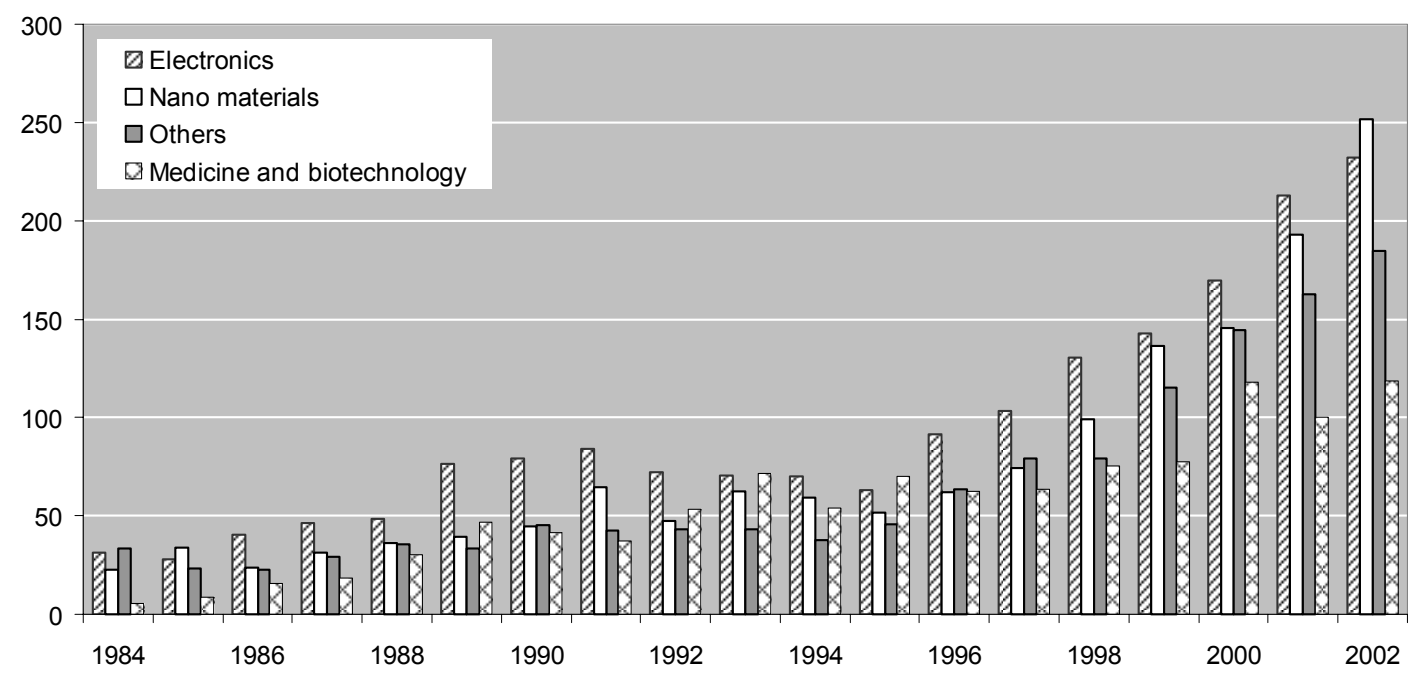


Figure 6 . Trends in nanotechnology patent applications by application fields (cont'd.)

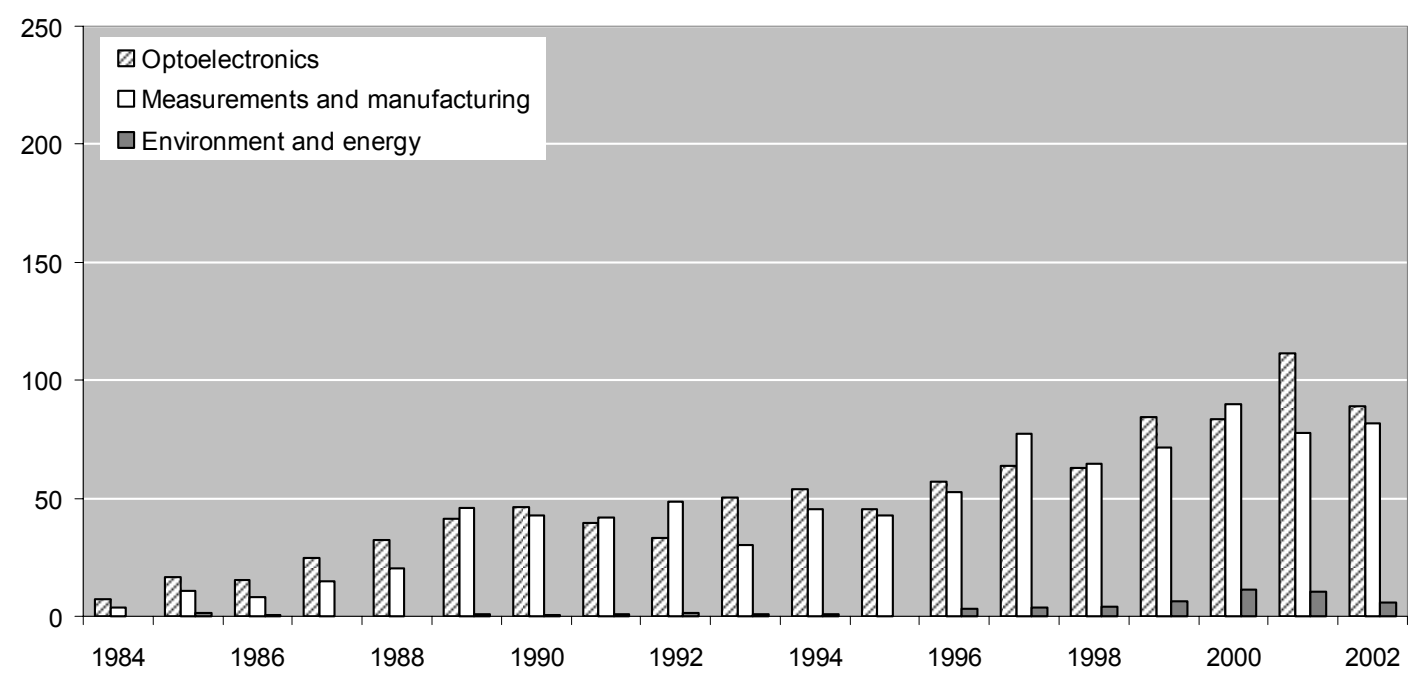

Note: Patent counts are based on the earliest priority date and fractional counts.

Source: OECD, Patent Database, September 2006 based on a list of patents selected by the EPO.

Then, how strongly do these bottom-up nanotechnologies link to other application fields? In order to study such linkages, the ratio of "Nano materials" in each application field was analysed. ${ }^{7}$ The presence of a high ratio of "Nano materials" characterises a technology that depends heavily on bottom-up nanotechnology or is vital in the development of bottom-up nanotechnology. ${ }^{8}$ The results for five application fields are shown in Figure 8.

The ratio of "Nano material" is small and almost constant in "Electronics" and "Optoelectronics". This trend suggests that applications of "Nano materials" in these application fields are seemingly not so common at present compared to the top-down processes. The relatively high ratios in "Medicine and biotechnology", "Measurements and manufacturing", and "Energy and environment" suggest nonnegligible linkages between bottom-up nanotechnologies and these application fields. Especially, the ratio in "Measurements and manufacturing" is increasing steadily over time. The increasing linkage between "Nano materials" and "Measurements and manufacturing" shows the vital role of "Measurements and manufacturing" in the development of bottom-up nanotechnologies.

The analysis presented here provides a view of nanotechnology development. Nanotechnology consists of a set of technologies on the nanometre scale, e.g. electronics, optoelectronics, medicine and biotechnology, etc. The majority of them are seemingly realised by the top-down process. Mutual interactions among these top-down nanotechnologies are weak ${ }^{9}$, because they are pushing their

7. Nanotechnology patent applications which have IPC related to "Nano materials" are counted in each application field. Denominators are the number of patent applications in each application field. The application fields of nanotechnology patent applications were assigned based on main IPC.

8. Direction of knowledge flow was not considered in this analysis. The indicator reflects both the influence of the bottom-up nanotechnologies on the application fields and the influence of the application fields on the bottom-up nanotechnologies.

9. Mutual interactions among nanotechnology patents in USPTO were analysed by Mayer. M. The study also pointed out that nanoscience and nanotechnology are considered a set of inter-related and overlapping but not necessarily merging technologies (Mayer, 2006b). 
technological frontier within their own fields. In addition to top-down nanotechnologies, there is another group of nanotechnologies that are realised by the bottom-up process. Intense efforts for the development of "Nano materials" have been made in the past decade. Knowledge of "Measurements and manufacturing" is becoming significant in the development of bottom-up nanotechnology. Nevertheless, the influence of these bottom-up nanotechnologies on application fields is currently small.

Figure 8. Linkage between "Nano materials" and the other five application fields

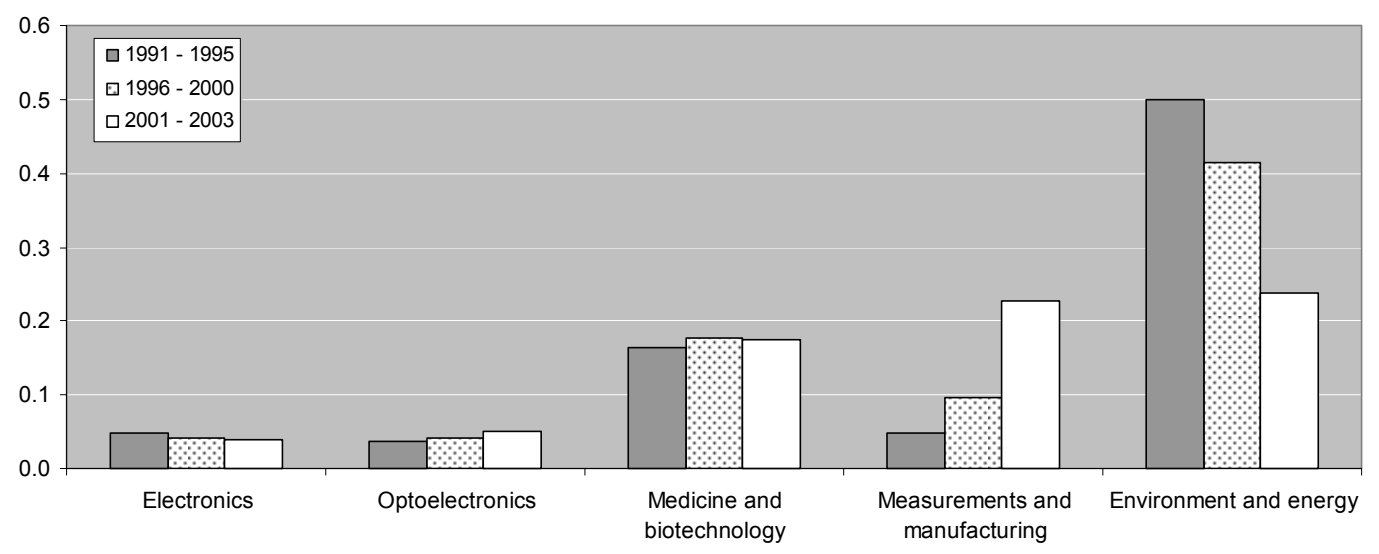

Note: Patent counts are based on the earliest priority date. The application field of a patent is identified based on the main IPC.

Source: OECD, Patent Database, September 2006 based on a list of patents selected by the EPO.

\subsection{Countries' shares in nanotechnology patent applications by application fields}

Current development of nanotechnology strongly relies on existing technologies and accumulated knowledge is crucial to its development. ${ }^{10}$ Countries' shares in nanotechnology patent applications by application fields were analysed (Figure 9). Countries' shares in total EPO applications whose main IPC falls into one of the six application fields were also shown for reference. A good correlation was found between overall characteristics of countries' shares in nanotechnology and total EPO applications, except for the European Union. For example, Japan holds the largest share in both nanotechnology and total EPO applications in "Electronics".

Japan has the largest share in "Electronics", "Optoelectronics" and "Environment". The United States holds the largest share in "Medicine and biotechnology", "Measurements and manufacturing", and "Nano materials". The European Union tends to have smaller shares in nanotechnology patent applications. Korea has the fourth largest share in nanotechnology related to "Electronics".

10. The importance of the cumulative knowledge in the development of nanotechnology was also pointed out by regional analysis (Zucker et al, 2006). 
Figure 9. Countries' shares in applications fields (1995-2003)

(a) Electronics

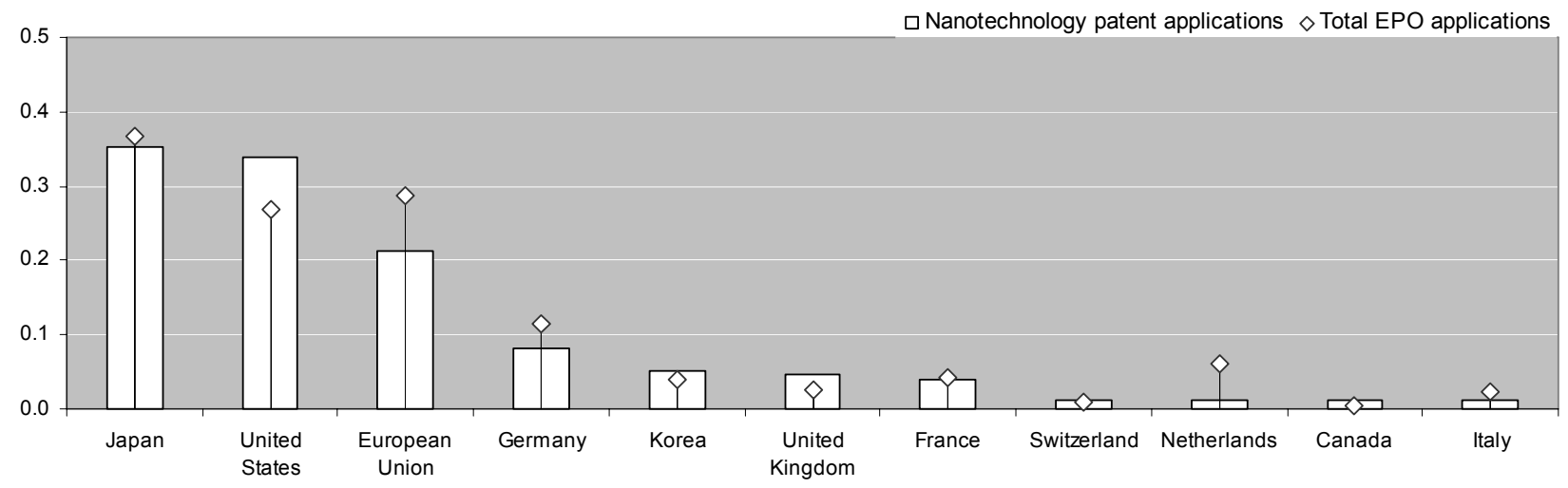

(b) Optoelectronics

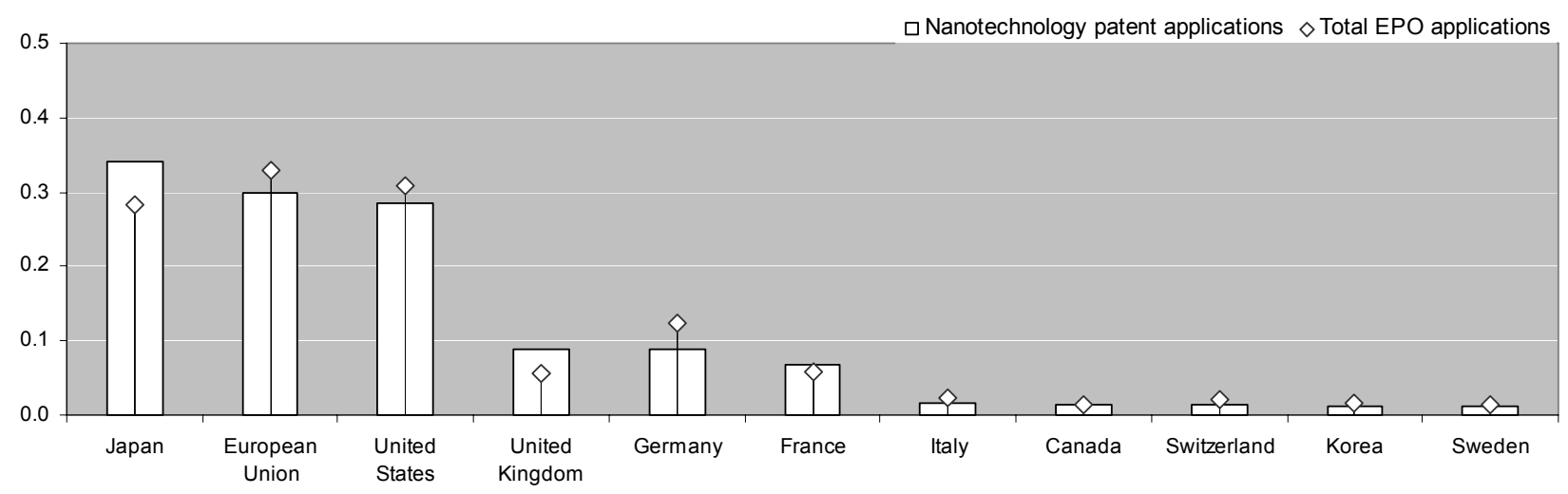

(c) Medicine and biotechnology

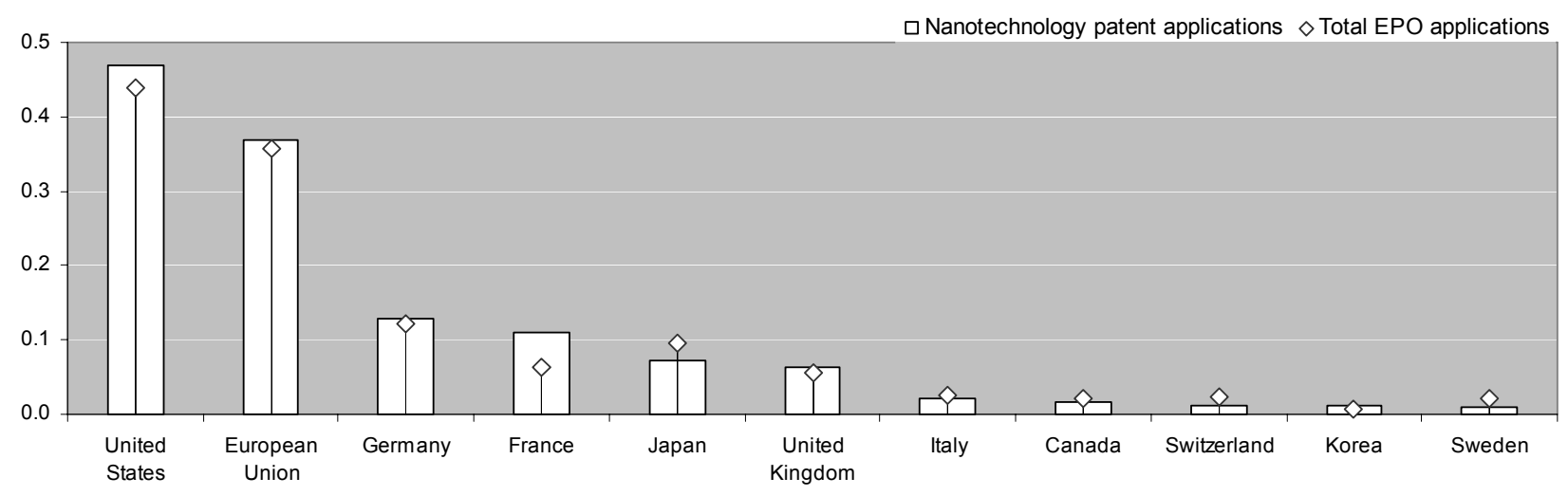


(d) Measurements and manufacturing

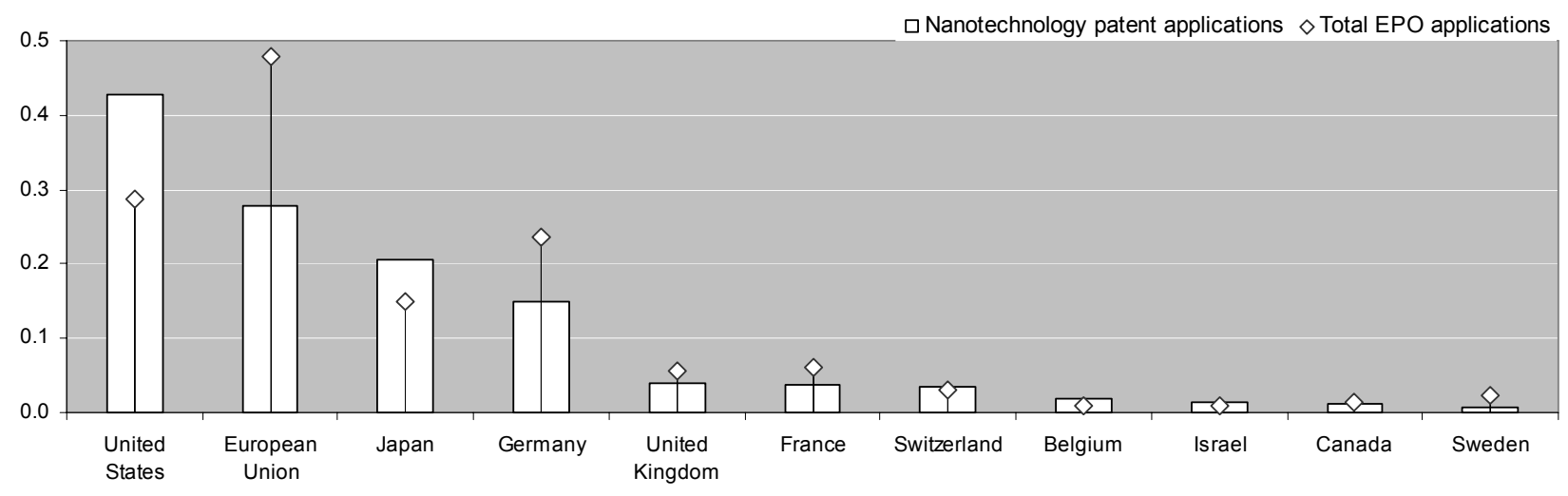

(e) Environment and energy

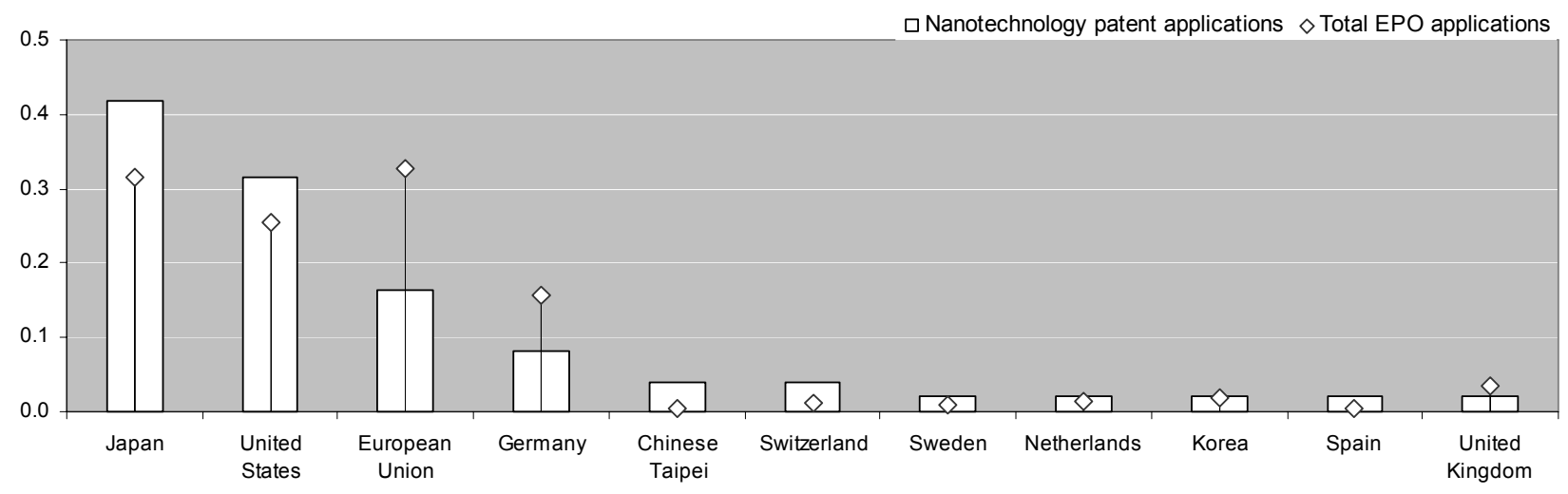

(f) Nano materials

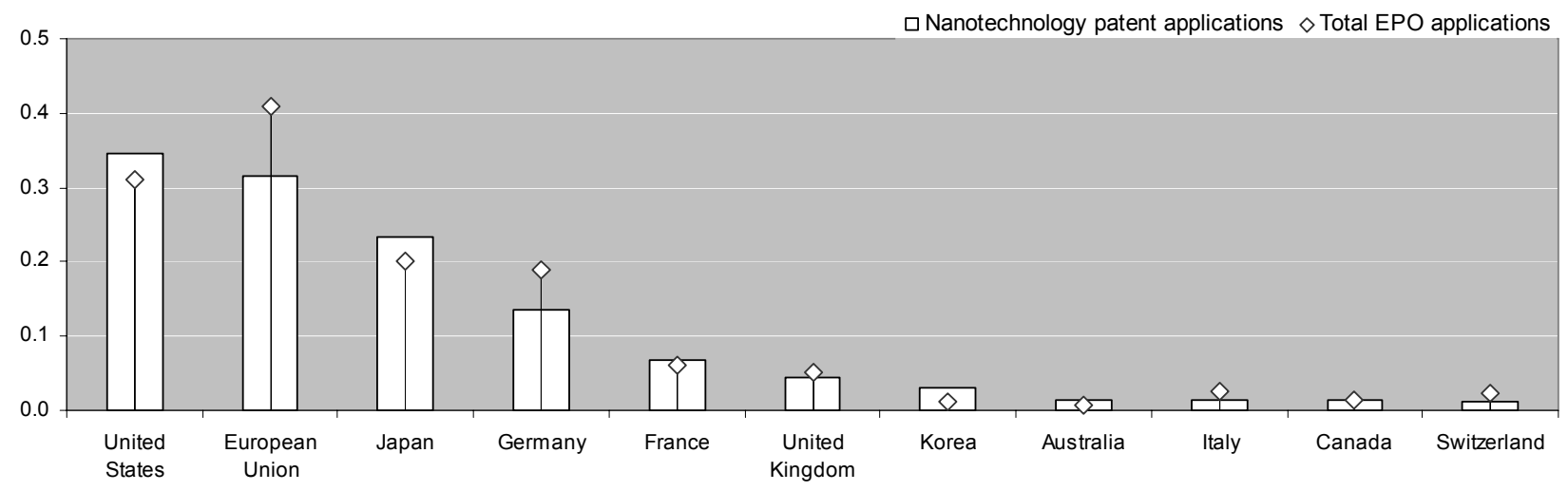

Note: Patent counts are based on the earliest priority date, the inventor's country of residence, and fractional counts. The application field of a patent is identified based on the main IPC.

Source: OECD, Patent Database, September 2006 based on a list of patents selected by the EPO. Sector classifications are based on the Eurostat sector attribution algorithm. 


\section{DSTI/DOC(2007)4}

\section{Citation analysis of nanotechnology patent applications}

The citation analysis of patents provides further insights into the characteristics of nanotechnology. Linkages between patent applications will shed light on how inventive activities relate to each other. There are two types of citations commonly analysed (see Figure 10).

Backward citations are citations from the nanotechnology patent applications to prior art. They represent the influence of past inventive activities on nanotechnology patent applications. The ratio of the NPL in citations is a proxy for measuring linkages between scientific and inventive activities (Narin et al, 1997; Harhoff 2003; Meyer, 2006a). Nanotechnology patent applications with a high ratio of NPL in citations can be considered as science-intensive inventions. Time-lags between nanotechnology patent applications and their prior art show how fast successive inventions are made. Sudden changes in time-lags would indicate technological breakthroughs or changes in technological trends.

Forward citations are citations to nanotechnology patent applications from other patent applications. The number of forward citations is considered to be an indicator of patents' economic or technological value (Lanjouw and Schankerman, 1999; Harhoff et al, 1999; 2003; Henderson et al, 1998; Jaffe et al, 2000).

Figure 10. Backward and forward citations

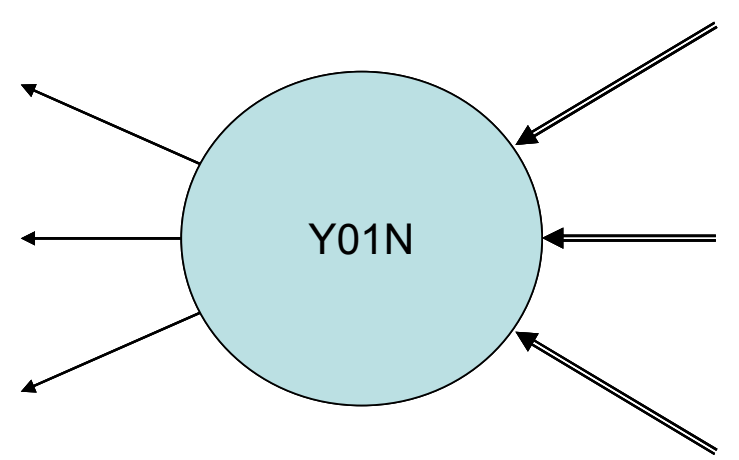

\footnotetext{
Backward citations (citations from Y01N) Forward citations (citations to Y01N)

- Linkage between scientific and inventive activities

- Technological value

- Influence of prior art on nanotechnology

- Economical value

- Influence of nanotechnology on successive inventions
}

\subsection{Backward citations}

\subsubsection{General properties}

Nanotechnology patent applications to the EPO (direct or via PCT) cite totally 34033 patents and 12264 non-patent literatures. ${ }^{11}$ The citations to the NPL account for $26.5 \%$ of the total citations (see Figure 11). The ratio of NPL citations in nanotechnology patent applications is higher than the ratio of NPL citations in total EPO applications (about 10\%). Figure 12 shows the average backward citations per nanotechnology patent application along with those in total EPO applications. It remained constant in the 1980s and gradually increased from 5.3 citations in 1989 to 6.8 citations in 1994. After the gradual

11. The citation information was retrieved from the OECD/EPO patent citations database 2006. Citation information for 7903 out of 8568 nanotechnology patent applications was found. The citation information was retrieved for over $90 \%$ of patent applications whose priority date ranges from 1979 to 2002. The coverage in 2003 is relatively small, citation information for about $70 \%$ of patent applications was found. 
increase, it began to decrease and fell to 5.5 citations in 2003. Nanotechnology patent applications tend to cite more documents compared to overall EPO applications, though trends are almost identical in both cases except for the early 1990s, when citations in nanotechnology patent applications are relatively larger than those in total EPO applications. Among the backward citations, approximately one-quarter consists of documents assigned to Y01N. The ratio of the citations to $\mathrm{Y} 01 \mathrm{~N}$ documents could be considered as an indicator showing how nanotechnology inventions rely on nanotechnology itself or other technologies. ${ }^{12}$

Ninety-nine percent of patents cited in nanotechnology patent applications were from the seven main patenting authorities, as shown in Figure 13. The ratios of the Japan Patent Office and the World Intellectual Property Organisation are larger than those obtained in the analysis for the total EPO applications.

Figure 11. The ratio of patent citations and NPL citations in the nanotechnology patent applications to the EPO from international and European searches (1978 - 2005)

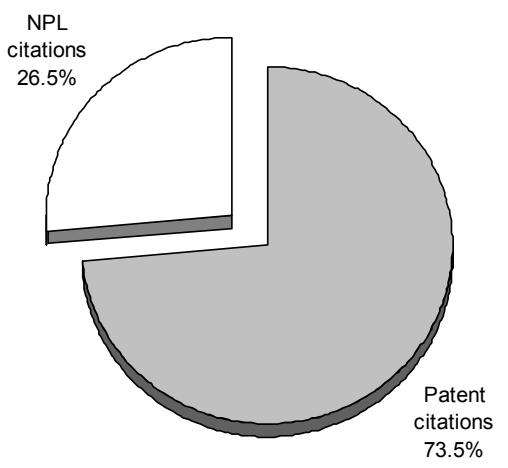

Note: Patent counts are based on the earliest priority date.

Source: OECD, EPO citations database September 2006 and OECD, Patent Database, September 2006, based on a list of patents selected by the EPO.

12. The degree of involvement of diverse technological fields is referred as a measure of "Originality" of the technology (Hall et al, 2001). But it is not sure, at the current stage, whether or not the same assumption works in this analysis. For example, if a nanotechnology patent is invented based on conventional miniaturisation technologies, the patent will refer to a non-nanotechnology patent and eventually have a high score in the originality indicator. 


\section{DSTI/DOC(2007)4}

Figure 12. Average backward citations per nanotechnology patent application and total EPO applications

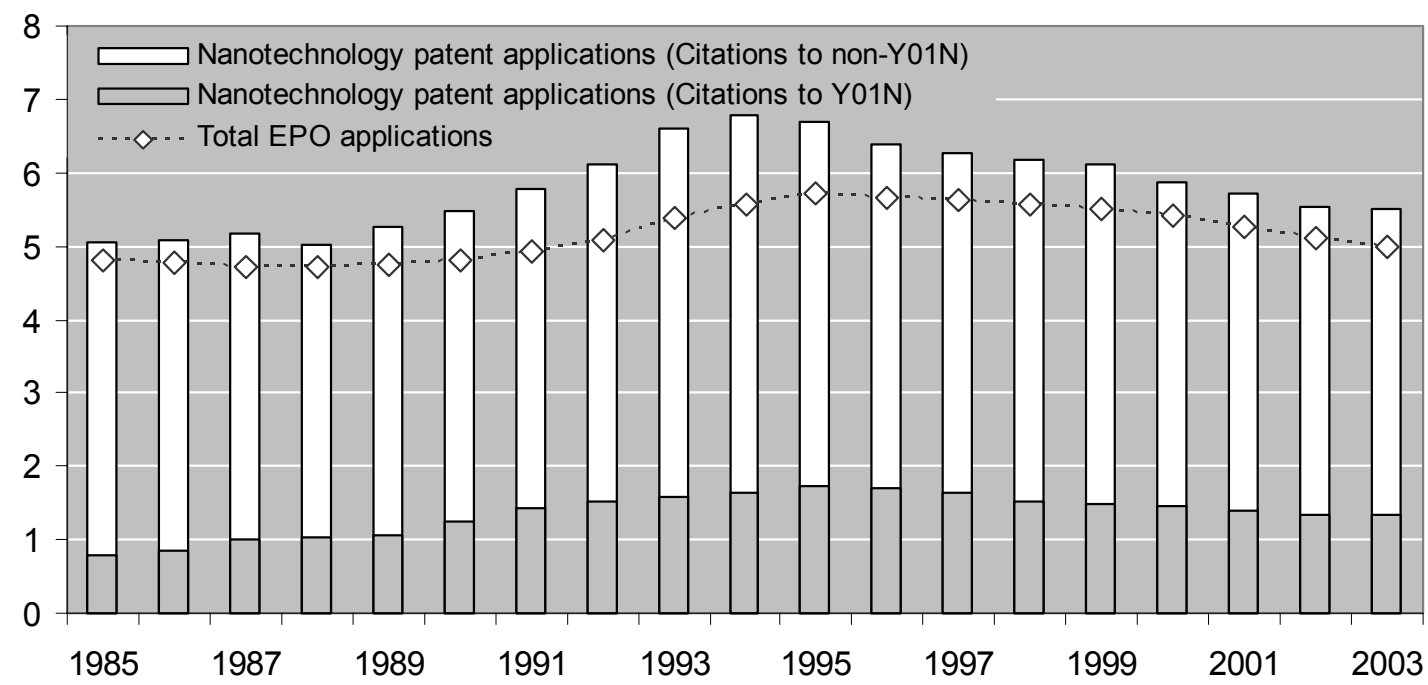

Note: Patent counts are based on the earliest priority date. Figure shows three years' moving average.

Source: OECD, EPO citations database September 2006 and OECD, Patent Database, September 2006, based on a list of patents selected by the EPO.

Figure 13. Distribution of patent citations in nanotechnology patent applications to the EPO from international and European searches (1995-2003)

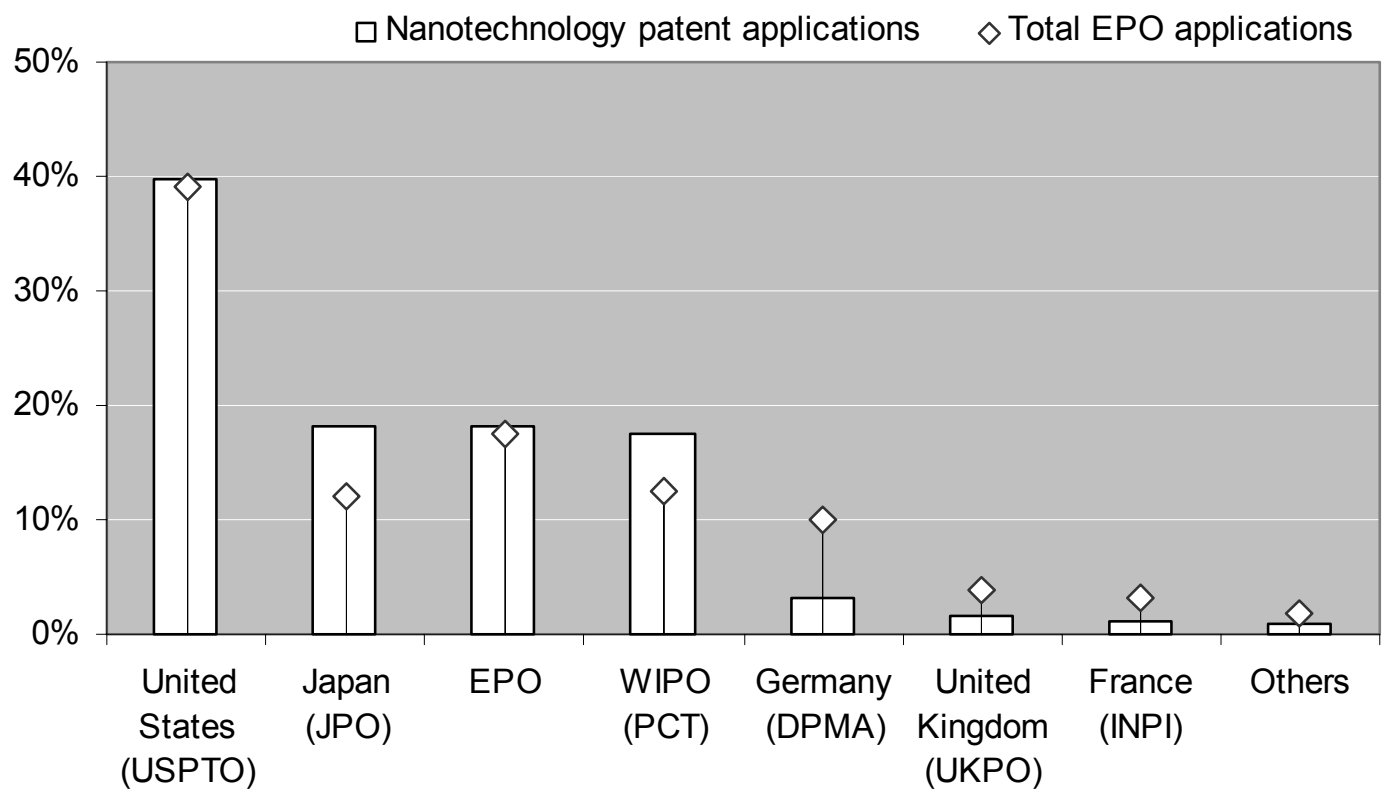

Note: Patents counts are based on the earliest priority date. The equivalence of publications from different patent authorities is not considered.

Source: OECD, EPO citations database September 2006 and OECD, Patent Database, September 2006, based on a list of patents selected by the EPO. 


\subsubsection{Linkages between scientific and inventive activities}

NPL citations are citations to non-patent literature associated with inventions claimed in the patent applications. Since the majority of NPL citations consist of citations to scientific journals, it is likely that the ratio of NPL citations in patent applications will be a good indicator to assess science-intensiveness of inventive activities.

The high NPL citation ratio means that scientific research is likely to have a crucial influence in the development of nanotechnology. The ratio of NPL citations in nanotechnology patent applications is shown in Figure 14. The ratio gradually increased from $28 \%$ in 1985 to $33 \%$ in 1988 . After that, it decreased continuously to $23 \%$ in 1996 and has been almost constant since then. The reason for the decline is unclear. In the same period, the ratio of the NPL citations in total EPO citations was almost constant at $10 \%{ }^{13}$ The detailed analysis (see Table 3 ) shows that $48.1 \%$ of nanotechnology patent applications do not cite any NPL. $34.9 \%$ of patent applications have $50 \%$ or less (and more than $0 \%$ ) NPL citations. $16.9 \%$ patent applications have more than 50\% NPL citations. This result indicates that nanotechnology patent applications can be classified into technology-intensive or science-intensive.

The next question is which patent applications are actually more science-intensive. The ratio of the NPL citations in nanotechnology patents by the six application fields is shown in Figure 15. The NPL ratio in "Medicine and biotechnology" is almost the same as that of overall EPO applications. In contrast, the other application fields have relatively larger shares in the NPL ratio.

Figure 14. The ratio of NPL citations in nanotechnology patent applications and total EPO applications

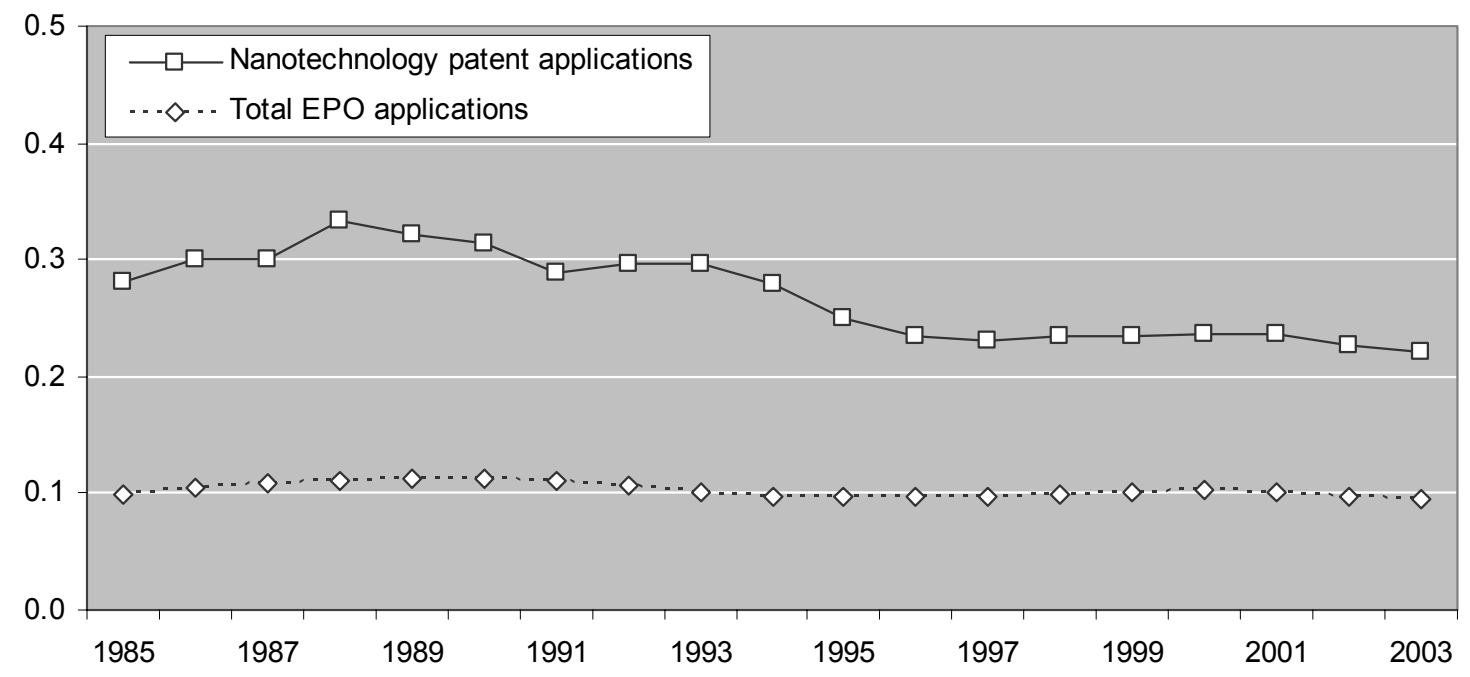

Note: Patent counts are based on the earliest priority date. Figure shows three years' moving average.

Source: OECD, EPO citations database September 2006 and OECD, Patent Database, September 2006, based on a list of patents selected by the EPO.

13. Preliminary analysis of NPL citation ratios in other emerging technologies registers $14 \%$ of NPL citations in information and communication technology and 53\% in biotechnology in the period 1995-2003. Technologies are identified by main IPC (OECD, 2006). The NPL ratio may greatly depend on characteristics of science and technology development. For example, in information and communication technology, outputs or outcomes are not commonly published as scientific literature, compared to nanotechnology and biotechnology. 
Table 3. The number and share of nanotechnology patent applications by intensity of NPL citation (1995-2005)

\begin{tabular}{lccc}
\hline & No NPL & $0 \% \sim 50 \%$ & $50 \% \sim 100 \%$ \\
\hline \hline $\begin{array}{l}\text { The ratio and the number of citations } \\
\text { to non-patent literature }\end{array}$ & $48.1 \%(2492)$ & $34.9 \%(1809)$ & $16.9 \%(875)$ \\
\hline
\end{tabular}

Note: Patent counts are based on the earliest priority date.

Source: OECD, EPO citations database September 2006 and OECD, Patent Database, September 2006, based on a list of patents selected by the EPO.

\section{Figure 15. The ratio of NPL citations in nanotechnology patent applications by application fields} (1995-2003)

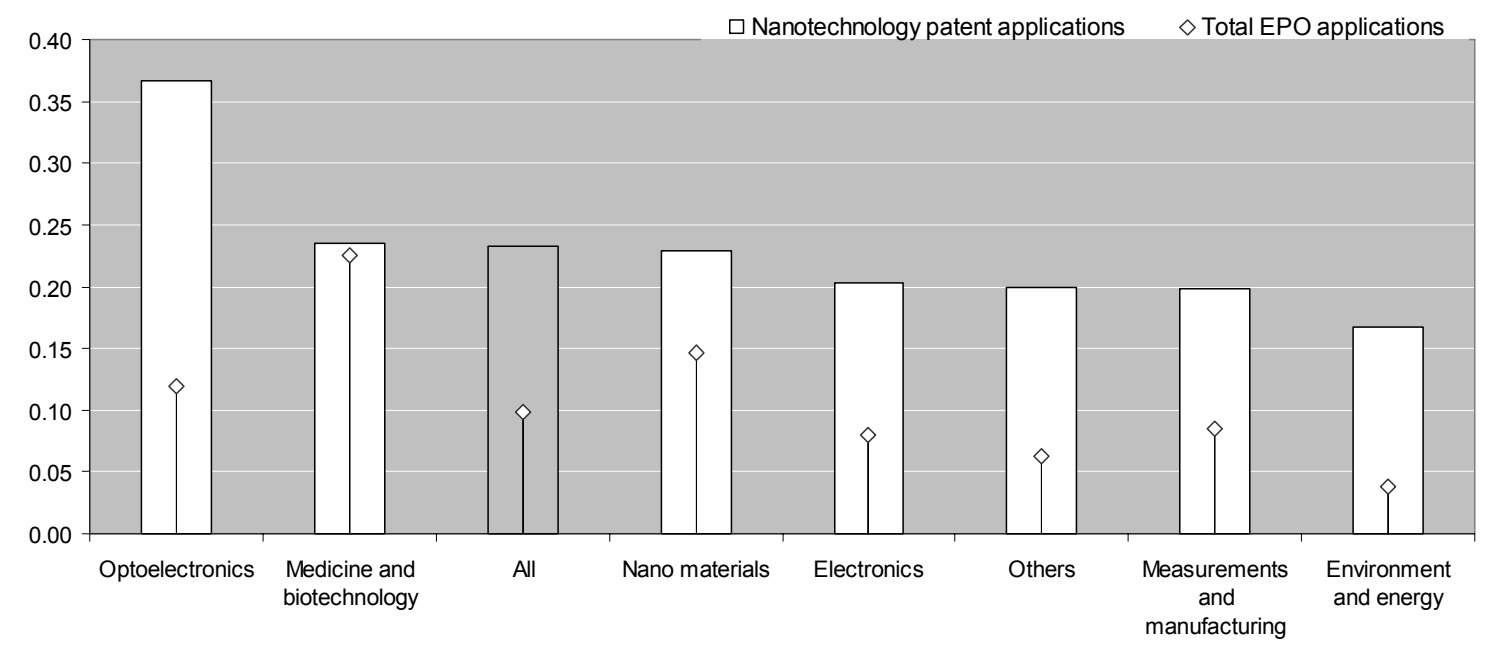

Note: Patent counts are based on the earliest priority date. The application field of a patent is identified based on the main IPC

Source: OECD, EPO citations database September 2006 and OECD, Patent Database, September 2006, based on a list of patents selected by the EPO.

Trends in the ratio of the NPL citations exemplify the changing nature of linkages between scientific research and inventive activities. Three typologies can be identified. The ratio of NPL citations stays constant in patent applications whose main IPC is A61K (Drug delivery and applications of $\mathrm{TiO}_{2}$ to sun screening) as shown in Figure 16(a), indicating continuous interactions between scientific and inventive activities. Meanwhile, the ratio of NPL citations in patent applications in H01L (Semiconductor devices) is notably large in the early stage and decreases over time, but remains substantial [see Figure 16(b)]. This trend could indicate that scientific research played a crucial role to spur inventive activities. The result is consistent with what was observed in a key phrase analysis where the convergence of fundamental concepts, e.g. quantum semiconductor devices, into specific technologies, e.g. semiconductor memories, was observed (see Appendix A. 3). In patent applications in C01B (Carbon nanotubes), the role of scientific knowledge has been growing, indicating that cutting-edge scientific research is directly linked to inventive activities in the case of this technology [see Figure 16(c)]. 
Figure 16. Trends in patent citations and NPL citations in nanotechnology patent applications (a) A61K, (b) H01L, and (c) C01B

(a) $\mathrm{A} 61 \mathrm{~K}$

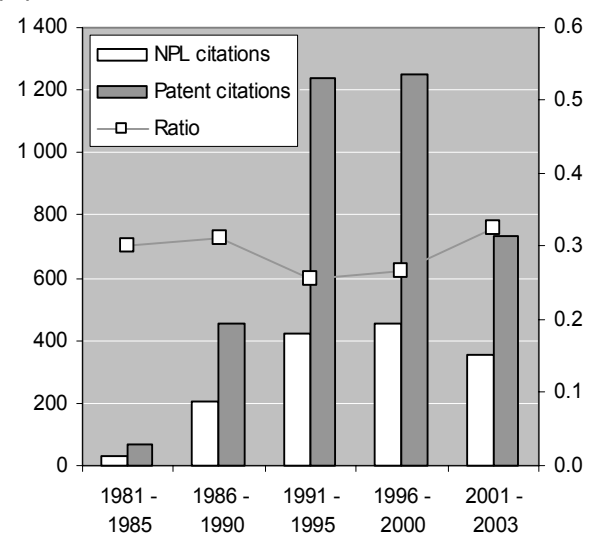

(b) H01L

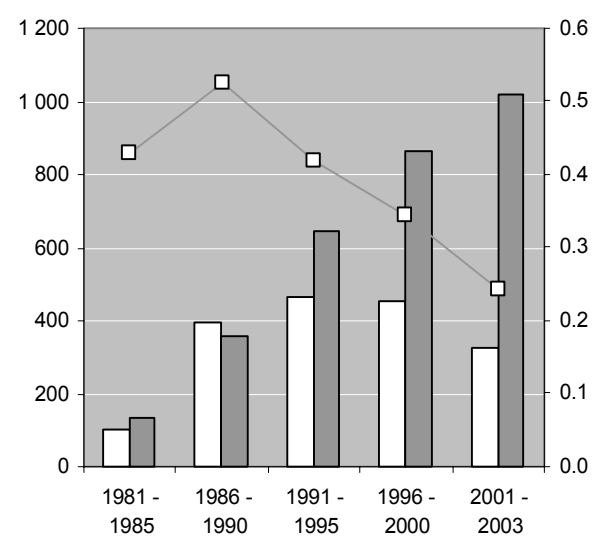

(c) $\mathrm{C} 01 \mathrm{~B}$

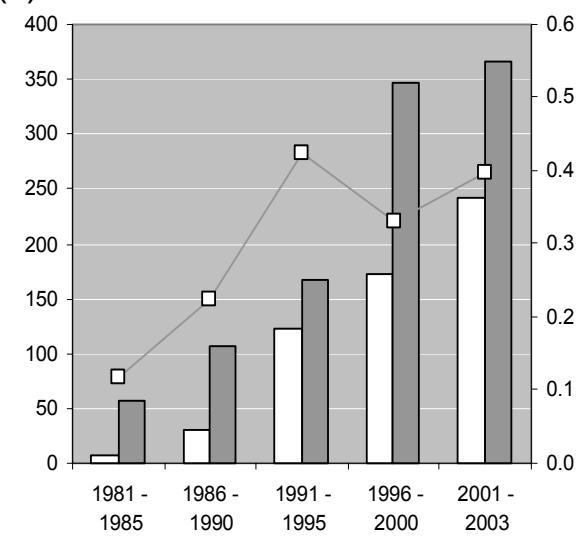

Note: Patent counts are based on the earliest priority date and the main IPC.

Source: OECD, EPO citations database, September 2006 and OECD Patent Database, September 2006, based on a list of patents selected by the EPO.

\subsubsection{Influence of prior arts on nanotechnology patent applications}

The analysis of citation time-lags helps assess lead times between successive inventions. This is a good measure for assessing the influence of prior art on current inventive activities. Patent applications which have long time-lags are considered to be slowly developing technologies. In contrast, short time-lags identify technologies in rapid development. Sudden changes in time-lags suggest the existence of technological breakthroughs or changes in technological trends.

In this analysis, time-lags were analysed based on differentials in priority date between nanotechnology patent applications and patent applications cited therein. Due to the limited data available, information on cited patent publications in the EPO, UTPTO, JPO, and WIPO was used in this analysis. ${ }^{14}$

14. The retrieval ratio of priority date information in the cited patent applications is at its lowest in 1978, about $30 \%$. The coverage gradually increased from 1978. It reached almost $90 \%$ in 1992 and has been constant since then. Absence of priority date information in the cited patent applications published via national patent offices in European countries such as Germany, the United Kingdom, and France, is a major reason for low coverage of the information in the 1980s, because citations to these three patent offices are expected to account for a large ratio of citations before the establishment of EPO and WIPO. 
As shown in Figure 13, these four patent authorities account for $90 \%$ of the total citations in nanotechnology patent applications in 1995-2003.

The most common time-lag is two years. The distribution of the citation time-lags obtained from all backward citations in the nanotechnology patent applications is shown in Figure 17. About $50 \%$ of the backward citations occur within four years and $90 \%$ of the citations occur within 15 years. The time-lag has a notably long tail. About $2.5 \%$ of citations have a time-lag of 25 years or more.

Figure 17. Distribution of time-lags between nanotechnology patent applications and citations therein (1995-2003)

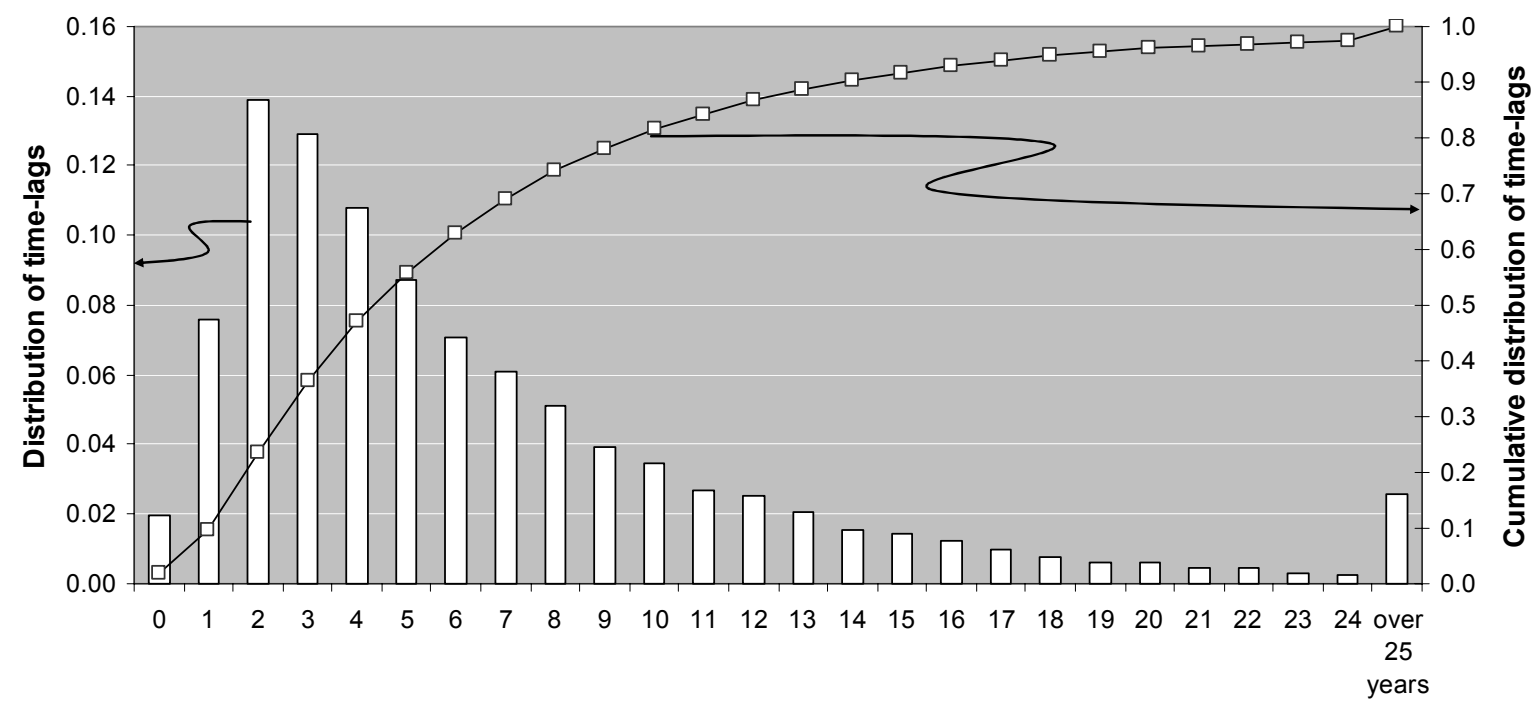

Note: Patent counts are based on the earliest priority date.

Source: OECD, EPO citations database September 2006 and OECD, Patent Database, September 2006, based on a list of patents selected by the EPO.

In order to analyse how time-lags between successive inventions vary by technology, the time-lags in selected IPC were analysed. The number of months accounting for $50 \%$ of the total backward citations from nanotechnology patent applications to prior patent publications was calculated. The calculation of time-lags was based on priority date. This indicator is known as the "citing half-life" in bibliometric analysis (Deurenberg, 1993).

Figure 18 shows four typical examples of trends in time-lags. The time-lags in H01L and A61K remain constant, especially in recent years. These technologies are considered to be developing incrementally and steadily over time. Patent applications in G01N have a dip in time-lags around the late 1980s. This remarkable shortening in the time-lags is attributable to the invention of the Scanning Tunnelling Microscope (STM) in 1982. The key phrase analysis of titles in patent applications validates the emergence of the STM in this period. The sudden drop in time-lags in H01J is due to technological development in flat panel displays. It exemplifies changes in technological trends. In the early 1990s, patent applications in H01J mainly focused on the development of electron beams. Applications of electron emission devices to flat panel displays dominate patent applications after 1995 and accelerated technology development.

Time-lags have been increasing in G11B and H01S. A sharp increase in time-lags is observed in H01S from the late 1990s onwards. Since technologies associated with lasers dominate patent applications of H01S, the technological breakthrough in blue lasers may have had some influence on this trend. This point could be unveiled by detailed analysis on threads of technology development through further citation analysis. 
A notable example of a sharp decrease in time-lags due to scientific discoveries is observed in C01B. In the mid-1980s, the time-lags in C01B were extremely long, indicating slow technology development. The time-lags surprisingly decreased from 1986 to 1993 and reached about 30 months in 1993. This sharp plunge in the time-lags is a consequence of successive discoveries of fullerenes and carbon nanotubes. ${ }^{15}$ These two carbon materials are considered to be key materials in nanotechnology due to their wide range of potential applications. The important influence of scientific activities is also observed, as reflected in the increasing NPL ratio in citations [see Figure 16(c)].

Figure 18. Trends in time-lags between nanotechnology patent applications and citations therein, four typical examples

(a)

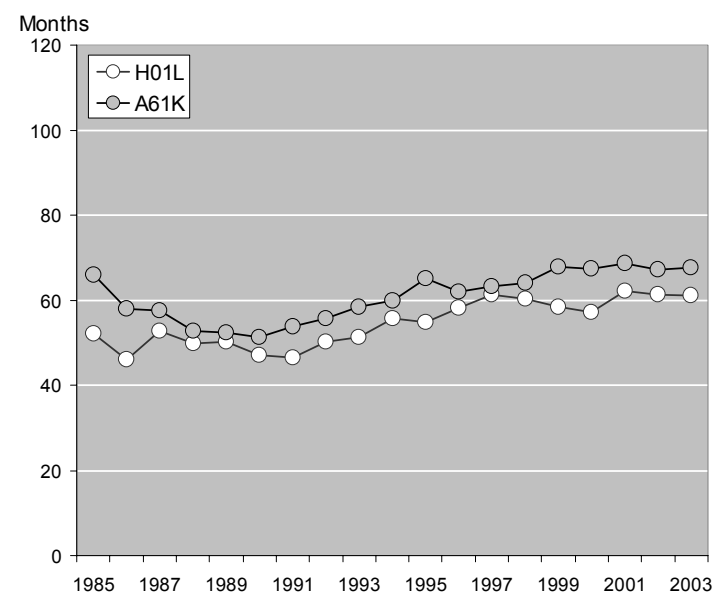

(c)

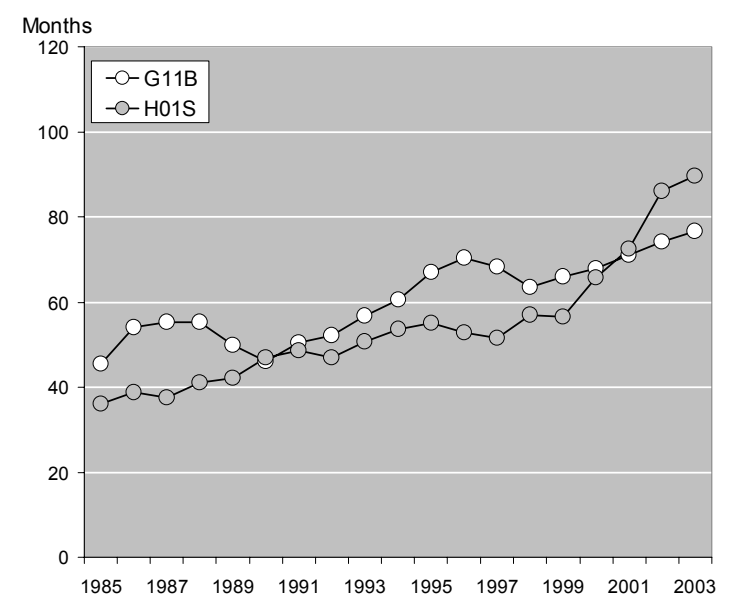

(b)

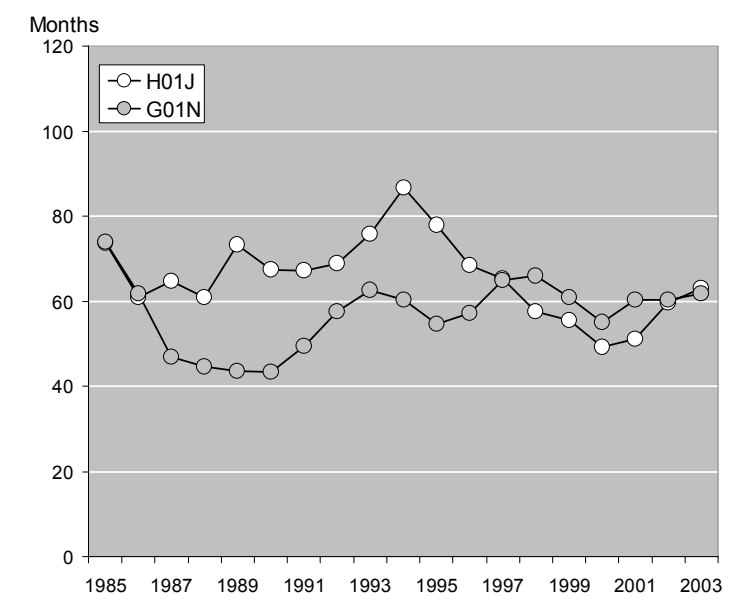

(d)

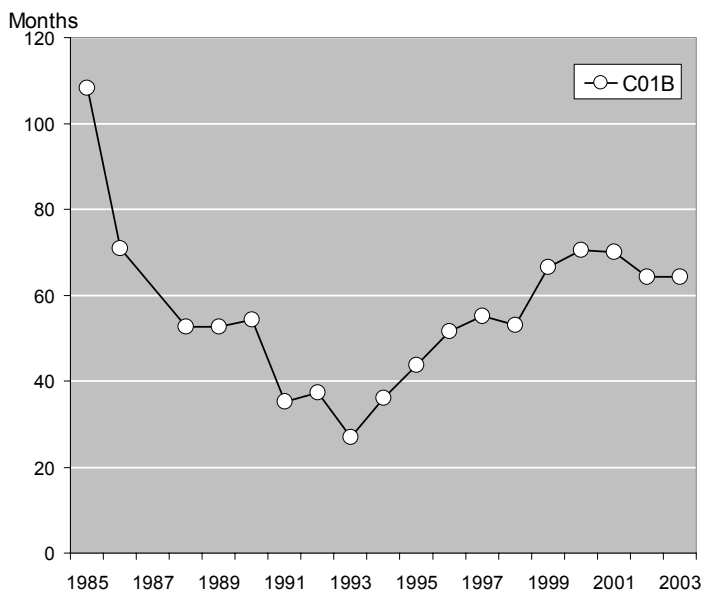

Note: Patent counts are based on the earliest priority date and the main IPC. Figures show three years' moving averages.

Source: OECD, EPO citations database September 2006 and OECD, Patent Database, September 2006, based on a list of patents selected by the EPO.

15. This explanation is based on indirect observations such as shortening in time-lags between successive invention and a notably high ratio of the NPL citations in C01B. Analysis of time-lags between patent publications and NPL will show direct evidence of a remarkable shortening of time-lags due to scientific discoveries. 


\section{2. $\quad$ Forward citations}

\subsubsection{General properties}

The number of forward citations to nanotechnology patent applications was also investigated. ${ }^{16}$ Counts in forward citations are commonly used as indicators of the economic or technological value of patents (Lanjouw and Schankerman, 1999; Harhoff et al., 1999; 2003; Henderson et al., 1998; Jaffe et al., 2000).

Trends of forward citations per nanotechnology patent application without truncation in the period of citation are shown in Figure 19. ${ }^{17}$ The citation is the largest, about 3.5, in 1987 and has been decreasing monotonically over time. These global trends are mainly attributable to different truncation durations in forward citations. Generally speaking, older patent applications have more occasions to be cited. In order to eliminate the effects of truncation, the forward citations received within five years from priority year were counted.

Figure 19. Trends in forward citations per patent application

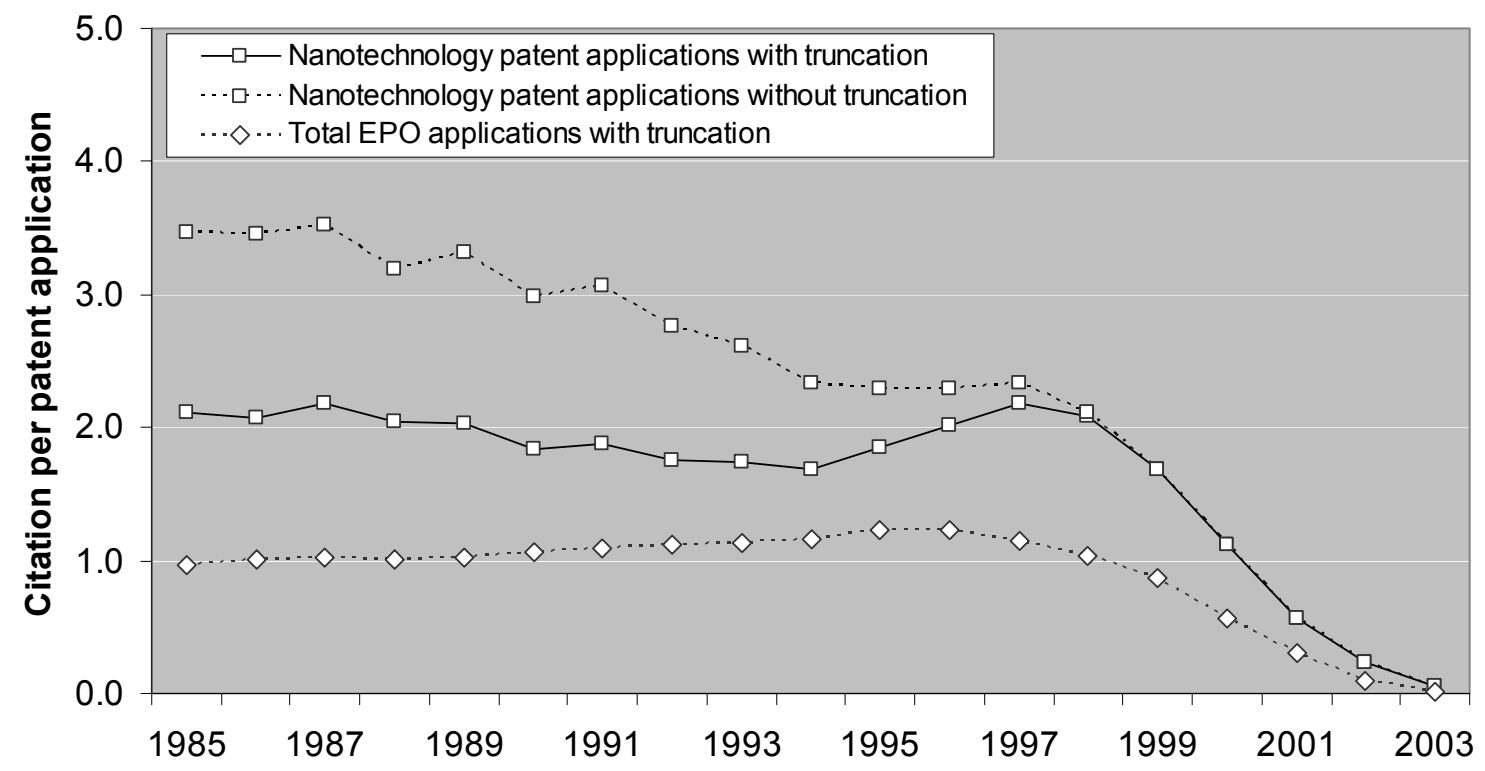

Note: Patent counts are based on the earliest priority date. Forward citations received within five years from priority year are counted. Figure shows three years' moving average.

Source: OECD, EPO citations database September 2006 and OECD, Patent Database, September 2006, based on a list of patents selected by the EPO.

The truncated forward citations show that nanotechnology patent applications are likely to receive more forward citations compared to total EPO applications. The truncated forward citations in

16. When a patent application is published by more than one office, any version of it can be cited in a search report (Webb et al, 2005). In this study, only the equivalence of patent applications between EPO and PCT publications was considered, i.e. forward citations only count citations to nanotechnology patent application published by EPO or WIPO. Thus, the forward citations counts presented here show partial views on forward citations to nanotechnology patent applications.

17. The figures presented here show average values of the forward citations. Because of skewed distribution of the forward citations, the average forward citations tend to be very small. 
nanotechnology patent applications are about twice as large as those in total EPO applications in 1985. The differentials between nanotechnology patent applications and total EPO applications gradually decreased and reached the minimum in 1994. After that, the differential increased sharply from 1994 to 1998. Nanotechnology patent applications in 1998 received twice as many citations as the total EPO applications. Decreasing trends after 2000 are probably due to the limited availability of data.

High citations to the nanotechnology patent applications suggest their high technological or economical value. ${ }^{18}$ The average number of citations by the six application fields is shown in Figure 20. "Medicine and biotechnology" has the largest average of forward citations. The citations to "Measurements and manufacturing" are significantly higher than the field average in total EPO applications. This is another rational showing that nanotechnologies related to "Measurements and manufacturing" have crucial roles in the development of nanotechnologies.

Among the nanotechnology patent applications, quite a limited number of nanotechnology patent applications likely have huge influences on the development of nanotechnology. Figure 21(a) shows the probability, $P(k)$, of nanotechnology patent applications getting $k$ forward citations. About half of patent applications get no forward citations to date. Patent applications getting four or less citations account for about $90 \%$ of total nanotechnology patent applications. The highest number of forward citations is 53 . Less than $1 \%$ of nanotechnology patent applications gets 15 or more citations.

Figure 20. Average forward citations per patent application in nanotechnology (1995-2003)

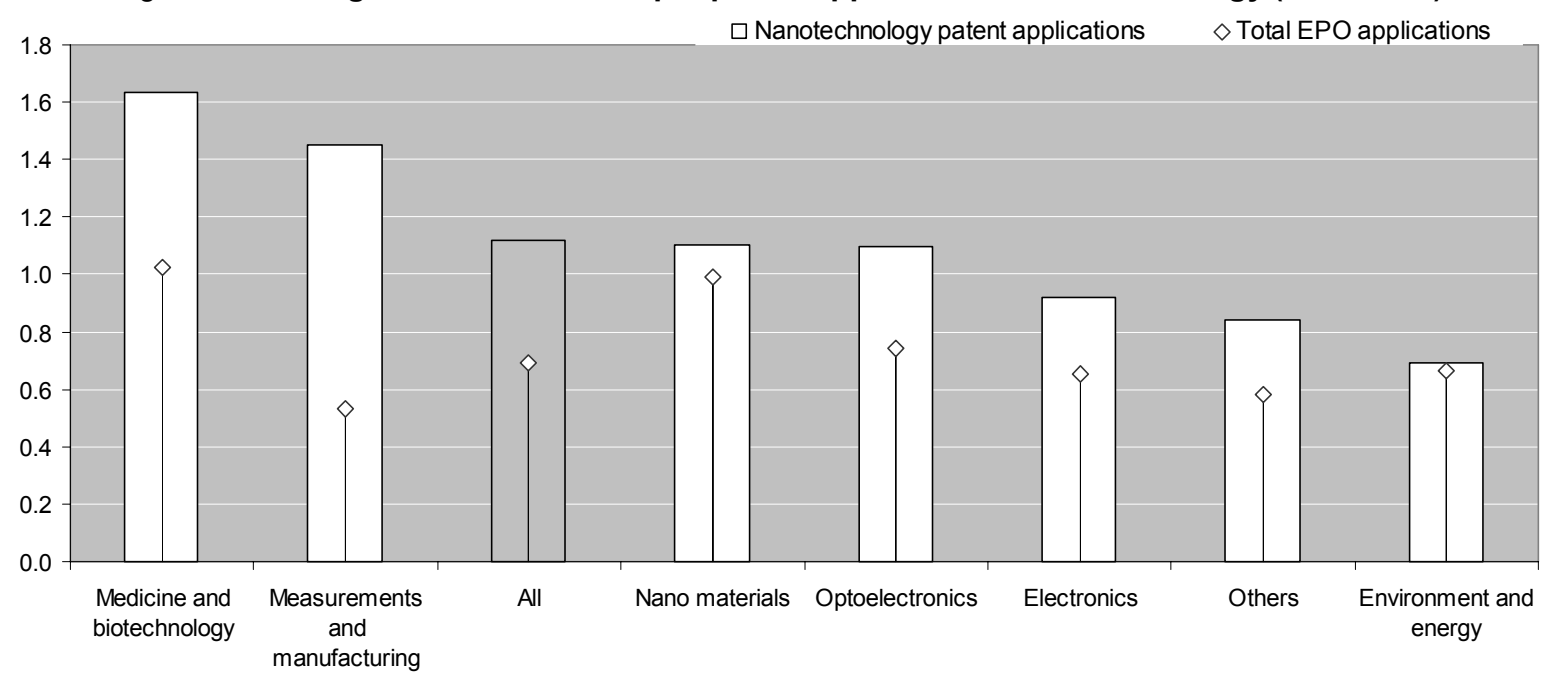

Note: Patent counts are based on the earliest priority date. The application field of a patent is identified based on the main IPC. No truncation in the period of forward citations.

Source: OECD, EPO citations database September 2006 and OECD, Patent Database, September 2006, based on a list of patents selected by the EPO.

18. The average forward citations per patent application to information and communication technology is 0.7 and biotechnology is 1.34 in the same time period. Technologies are identified by main IPC (OECD, 2006). 
Figure 21. (a) Probabilities, $P(k)$, of nanotechnology patent applications getting $\boldsymbol{k}$ forward citations,

(a)

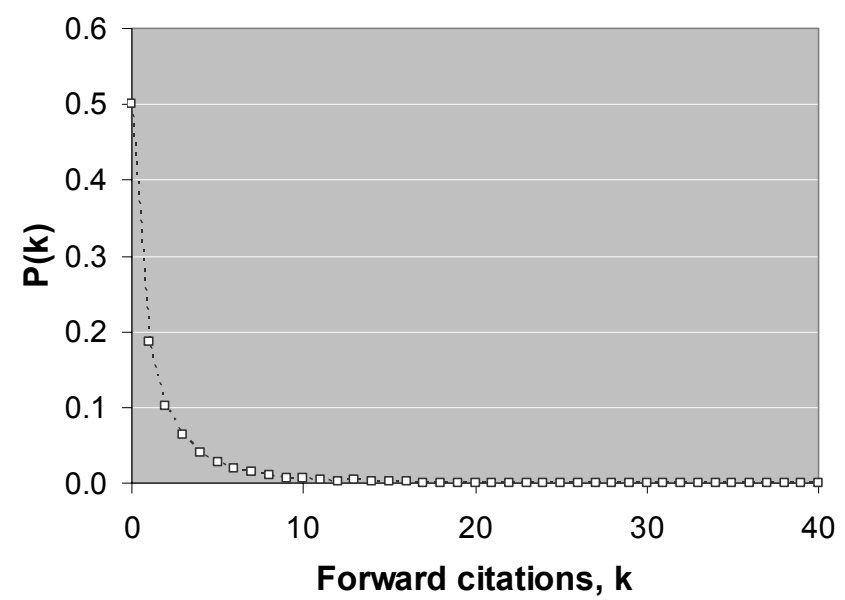

(b)

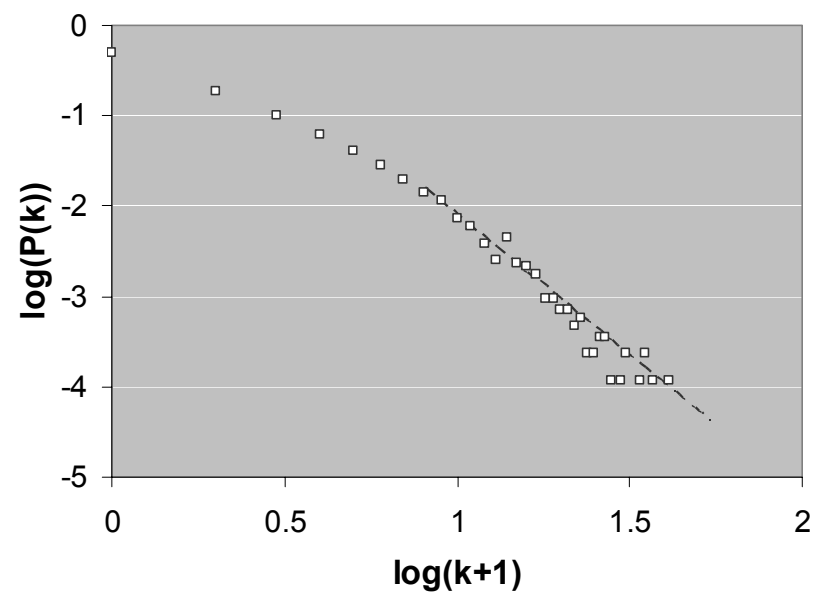

Note: Patent counts are based on the earliest priority date. No truncation in the period of forward citations.

Source: OECD, EPO citations database September 2006 and OECD, Patent Database, September 2006, based on a list of patents selected by the EPO.

The citation network in nanotechnology patent applications is scale-free (Newman et al 2006 and references therein). The preliminary analysis of the distribution of forward citations in nanotechnology patent applications indicates that the probability of nanotechnology patent applications with $k$ forward citations decreases as a function of $k$ by a power law with the exponent of about 3 [see Figure 21(b)]. The skewed profile suggests the existence of a preferential-attachment mechanism in patent citations, i.e. the rich get richer. ${ }^{19}$ Does this show the crucial roles of highly cited patent applications or simply reflect examiners' tendency to cite the same patent applications? The analysis of citation networks in nanotechnology patent applications would reveal a more concrete picture of the role of these highly cited patents in the development of nanotechnology.

\subsubsection{Distribution of forward citations by sectors}

The higher education sector produced the higher ratio of frequently cited patent applications. The sector analysis of forward citations, shown in Figure 22, reveals that approximately $10 \%$ of the nanotechnology patent applications from the higher education sector get five or more forward citations. About $1 \%$ of the nanotechnology patent applications get 11 or more citations. Of course, the majority of frequently cited patent applications come from the business enterprise sectors, because they account for $80 \%$ of all nanotechnology patent applications, as shown in Figure 5. However, the relatively high share of the frequently cited patent applications registers the crucial role of the higher education sector in knowledge creation and flow in nanotechnology.

19. Two mechanisms are crucial in the emergence of scale-free networks (Barabási and Albert, 1999). First, the network should grow over time, new patent applications being added continuously to it. Second, patent applications gain new citations in proportion to the number of citations they already have, the process is known as preferential attachment. 
Figure 22. Distribution of forward citations by sectors (1995-2003)

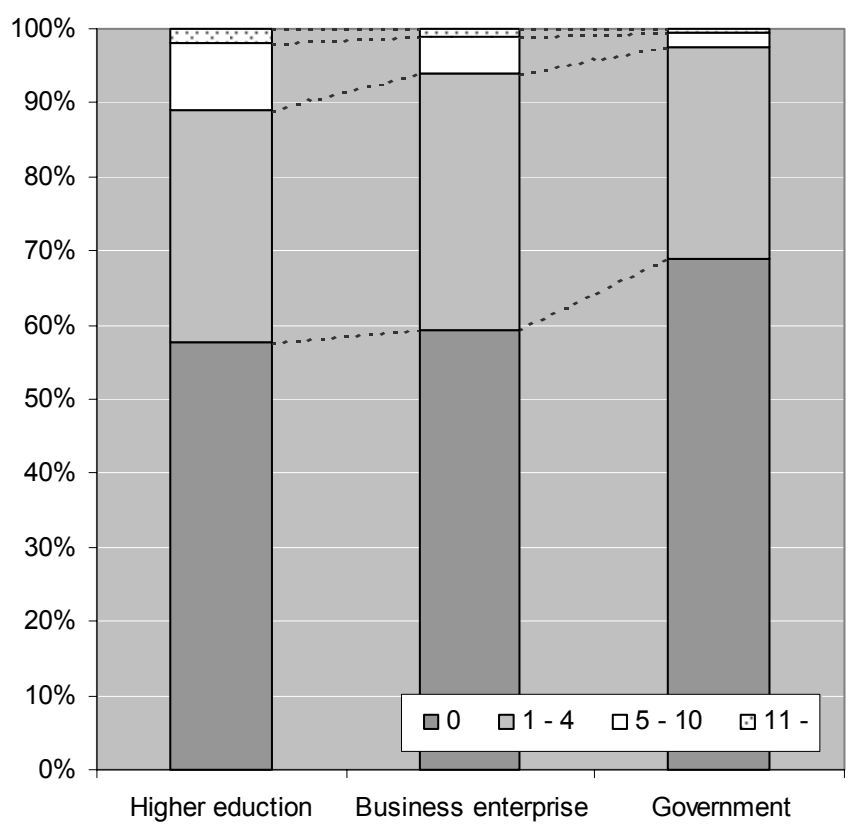

Note: Patent counts are based on the earliest priority date, the applicant's sector and country of residence, and fractional counts. No truncation in the period of forward citations.

Source: OECD, EPO citations database September 2006 and OECD, Patent Database, September 2006, based on a list of patents selected by the EPO.

\subsubsection{Relation between the breadth of a technology and forward citations}

The number of IPC can be taken as an indicator of technological openness. Generally, a few IPC codes are attributed to a patent application in order to assign fields of technology. In order not to assign too many codes, there are some rules such as "First place rule" or "Last place rule". ${ }^{20}$ However, if a patent application is a fundamental invention that has many potential applications, it is difficult to represent the patent application via a few IPC. It could be said that if the technology is broad-based, then the patent application might be assigned more IPC.

The breadth of a technology might also be related to its technological or economic value as reflected in its possible influence on a wider range of technologies. In this analysis, the relation between the breadth of technologies and forward citations was analysed. Figure 23 shows the average of forward citations as a function of the number of application fields. The forward citations received within five years from priority year were counted in order to eliminate truncation effects. The increase in application fields likely has a positive influence on forward citations except for "Optoelectronics". Differences in the growth rate by

20. First Place Rule: In some parts of IPC, where the "First Place Rule" is applied, a technical point of the invention is classified in the place which appears first in that part of the classification. When several specific technical points are written into the patent specifications, the "First Place Rule" is separately applied to them. Last Place Rule: In certain parts of IPC, where a specific technical point is covered by plural areas at the same hierarchy, the "Last Place Rule" is applied. According to this rule, such a technical point is classified in the place which appears last in that part of the classification. 
application field would indicate that the breadth of a technology has different effects on its technological or economic value depending on the application fields. ${ }^{21}$

Figure 23. Distribution of forward citations by fields (1978-2002)

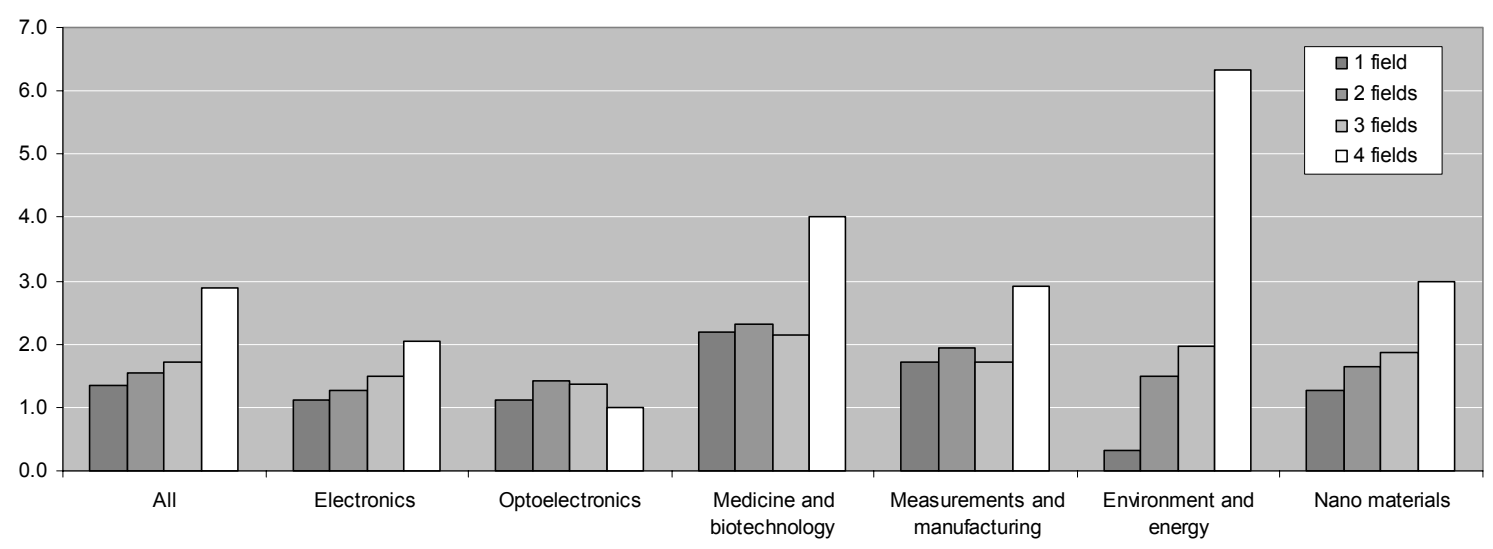

Note: Patent counts are based on the earliest priority date. Forward citations received within five years from priority year are counted.

Source: OECD, EPO citations database September 2006 and OECD, Patent Database, September 2006, based on a list of patents selected by the EPO.

\section{Conclusions and future work}

This analysis aims at capturing current inventive activities in nanotechnologies based on the analysis of patent applications to the EPO. The current status of nanotechnology, the recent acceleration in inventive activities, and the strong linkages between scientific and inventive activities have been documented.

\subsection{Nanotechnology: a set of technologies on the nanometre scale, not a single technological field}

The analysis presented here provides a current view on nanotechnology. Nanotechnology is a multifaceted technology. At present, it consists of a set of technologies on the nanometre scale rather than a single technological field. It covers "Electronics", "Optoelectronics", "Medicine and biotechnology", "Measurements and manufacturing", "Environment and energy", and "Nano materials".

The majority of nanotechnologies, especially nanotechnologies related to "Electronics" and "Optoelectronics", are seemingly realised by a top-down process, where nano-structures are developed through the improvement or advancement of existing technologies. Mutual interactions among these topdown nanotechnologies are seemingly weak, because they are usually pushing the technological frontier within their own fields. As they built on cumulative knowledge, top-down nanotechnologies are likely to have social and economic impacts in the short and medium term.

In addition to top-down nanotechnology, another group of nanotechnologies is developed by a bottom-up process. The development of such technologies has been particularly intense in the past decade and fuelled by scientific discoveries such as carbon nanotubes and fullerenes. The increasing importance of "Measurements and manufacturing" in the development of bottom-up nanotechnology was also observed.

21. The results presented here are only initial attempts at exploring the relation between the breadth of technologies and forward citations. Further analysis is needed to rationalise the results. The comparison between nanotechnology patents and total EPO applications will unveil whether or not the tendencies observed here are characteristics peculiar to nanotechnology patent applications. 
At this stage, bottom-up nanotechnology is likely to have a relatively low impact on application fields. It will take a while until bottom-up nanotechnologies show social and economic impacts. For example, the social application of "Single-electron memory devices" is forecast for 2025 , according to the latest technology foresight in Japan (NISTEP, 2005).

Nanotechnology not only covers a wide range of technologies, but also underpins the development of many fields. High citations to nanotechnology patent applications are likely to point to their high technological or economic value.

\subsection{The recent rise of inventive activities in nanotechnology}

Nanotechnology patent applications to the EPO have been increasing since the 1980s, except for a temporary stagnation in the early 1990s. The increase, especially remarkable since the end of the 1990s, has been higher than the average growth in the total number of EPO applications.

The United States, the European Union and Japan account for almost the same share in nanotechnology patent applications to the EPO, with the United States and Japan holding a relatively higher share in comparison to their total EPO average.

The current development of nanotechnology strongly relies on countries' existing technologies and accumulated scientific knowledge. Japan has the largest share in "Electronics", "Optoelectronics", and "Environment and energy". The United States holds the largest share in "Medicine and biotechnology", "Measurements and manufacturing", and "Nano materials". Countries' shares in the nanotechnology patent applications in each application field are strongly correlated with their shares in non-nanotechnology patent applications in the same fields except for the European Union.

Other countries are increasingly contributing to nanotechnology inventive activities, especially Korea which holds the fourth largest share in nanotechnology related to "Electronics". The rising importance of China, which was documented by an analysis of scientific literature (Zhou and Leydesdorff, 2006; Igami and Saka, 2007), has not been observed so far. This could be the reflection of time-lags incurring between the development of inventive activity in a field and its translation into scientific knowledge as reflected in bibliometric indicators.

Higher education and government sectors are an important source of knowledge in nanotechnology. Their shares in nanotechnology patent applications are notably larger than in the EPO average for all patent applications. The contributions of these sectors have become particularly important since the middle of the 1990s. Because of differences in national science, technology and innovation systems, the shares of government and higher education sectors vary across countries. The share of the government sector is the largest in France and Japan. The higher education sector holds a relatively large share in the United Kingdom, the United States, and the Netherlands. The private non-profit sector holds the largest share in Germany.

\subsection{Science fuels technological development in diverse ways}

Science fuels nanotechnology in diverse ways. An analysis of citations to non-patent literature shows the importance of interactions between scientific and inventive activities in nanotechnology.

Diverse interaction between scientific and inventive activities shows the significance of flexible promotion of research and development considering the nature of technologies. Three typologies of interactions can be distinguished. First, some inventive activities are spurred by scientific activities. These technologies show a relatively large share of non-patent literature in the initial stage of development, e.g. semiconductor devices. Second, some technologies are continuously fuelled by science, as revealed by 
their almost constant share of non-patent literature, e.g. drug delivery and applications of titanium dioxide to sun screening. Finally, there are some technologies for which the linkage between science and technology becomes important over time, e.g. carbon nanotubes.

Scientific activities have a crucial role in knowledge creation and flow in nanotechnology. Measurements of citation time-lags showed a remarkable shortening of the time-lags sparked by scientific breakthroughs, e.g. the discovery of carbon nanotubes. Citation analysis shows that the higher education sector produces a relatively high share of frequently cited patent publications.

\subsection{Future work}

The analysis presented here unveiled basic characteristics in nanotechnology in terms of inventive activities. However, several issues are still to be addressed. Further analysis will shed light on the following:

One issue worth pursuing is the analysis of the drivers of the recent rapid development of nanotechnology in spite of a slowdown in total EPO applications. Do these trends reflect national science and technology policies or strategies of business enterprises? Linking existing science and technology indicators, for example gross domestic expenditure on research and development, with the results presented here may provide some insights into this issue.

Another explanation could have to do with technological evolution. Could some successive scientific or technological breakthroughs have been spurring inventive activities in nanotechnology, especially bottom-up nanotechnologies? Combining information on both forward and backward citations, the evolution of nanotechnology patent applications will be traced. The analysis will show how the nanotechnology patent applications are related to each other and are changing over time. A map showing connections among nanotechnology patents, i.e. the mapping of nanotechnology patent applications (Börner et al, 2003 and references therein; Boyack, 2004 and references therein; Chen, 1999; Chen and Paul, 2001; Shiffrin and Börner, 2004, Mane, K, K. and Börner, 2004), will shed light on interactions among bottom-up and top-down nanotechnologies. Longitudinal analysis will show how nanotechnology has been evolving over time.

By tracing technological threads connected via citations, it will be shown whether frequently cited patent applications do actually play a role in the development of nanotechnology or are simply cited as prior arts for rejecting other patent applications. The mapping will also contribute to the understanding of how science and technology are interacting with each other and co-evolving over time (Murray, 2002).

Econometric analysis is also promising. The analysis presented here suggests that the breadth of a technology is a useful indicator for assessing its technological or economic value. There have been many attempts at assessing the technological or economic value of patent applications and various kinds of indicators were introduced (Lanjouw and Schankerman, 1999; Harhoff et al, 1999; 2003; Henderson et al, 1998; Jaffe et al, 2000). Identification of important determinants of economic and technological values of nanotechnology patents among the various indicators, e.g. backward citations, science linkages, and so forth, could help in patents' evaluation.

Finally, it should be emphasised that this study limits the analysis to patent applications filed at the EPO (direct or via PCT). Therefore, the results presented are not necessarily representative of trends in inventive activities in the world. In particular, activity in non-European countries, especially in the United States and Asian countries, may be underestimated. Both the analysis of nanotechnology patents in triadic patent families and the use of the World Statistical Patent Database (PATSTAT) by the EPO, can help provide a more comprehensive understanding of global knowledge creation and flows in nanotechnology. 
DSTI/DOC(2007)4

\section{ANNEX A}

\section{OTHER BASIC STATISTICS IN THE NANOTECHNOLOGY PATENT APPLICATIONS}

\section{A.1. Inventive activities in business enterprises}

The share and number of business enterprises which own a small (1-5 patents), medium (6-50 patents), and large (over 50 patents) number of nanotechnology patent applications is shown in Table 4. Business enterprises with a small number of patent applications account for approximately $90 \%$ of the total nanotechnology patent applications in the European Union and the United States. In contrast, the ratio is about $80 \%$, (10\% less), in Japan. The ratio of business enterprises owning a large number of patent applications is about 3\% in Japan, the ratio is roughly six and three times larger than the ratio in the European Union and the United States respectively.

The dominancy of the large patenting business enterprises in Japan is characteristically observed in their shares in the nanotechnology patent applications. Table 5 shows the share and number of patent applications owned by the business enterprises, different in sizes of patent applications. In Japan, the large patenting business enterprises account for more than $50 \%$ of the total patent applications. These ratios are $11.8 \%$ in the European Union and $22.9 \%$ in the United States. The contribution of small patenting business enterprises in the European Union and the United States (about 40\%) is approximately double in comparison to that in Japan (about 20\%).

Table 4. The share and number of business enterprises via the number of nanotechnology patent applications (1978-2005)

\begin{tabular}{cccccc}
\hline & 1 & $2-5$ & $6-15$ & $16-50$ & $51-$ \\
\hline \hline European Union & $61.3 \%(358)$ & $27.2 \%(159)$ & $7.5 \%(44)$ & $3.4 \%(20)$ & $0.5 \%(3)$ \\
United States & $53.9 \%(329)$ & $34.3 \%(209)$ & $7.4 \%(45)$ & $3.4 \%(21)$ & $1.0 \%(6)$ \\
Japan & $48.0 \%(158)$ & $33.4 \%(110)$ & $11.2 \%(37)$ & $4.0 \%(13)$ & $3.3 \%(11)$ \\
\hline
\end{tabular}

Note: Patent counts are based on the earliest priority date, the applicant's sector and country of residence, and whole counts.

Source: OECD, Patent Database, September 2006, based on a list of patents selected by the EPO. Sector classifications are based on the Eurostat sector attribution algorithm.

Table 5. The share and number of nanotechnology patent applications from business enterprises via the number of applications (1978-2005)

\begin{tabular}{cccccc}
\hline & 1 & $2-5$ & $6-15$ & $16-50$ & $51-$ \\
\hline \hline European Union & $18.4 \%(358)$ & $22.8 \%(444)$ & $19.6 \%(382)$ & $27.4 \%(532)$ & $11.8 \%(229)$ \\
United States & $13.3 \%(329)$ & $24.0 \%(595)$ & $16.2 \%(400)$ & $23.6 \%(584)$ & $22.9 \%(567)$ \\
Japan & $6.3 \%(158)$ & $12.2 \%(305)$ & $14.0 \%(351)$ & $15.0 \%(375)$ & $52.5 \%(1312)$ \\
\hline
\end{tabular}

Note: Patent counts are based on the earliest priority date, the applicant's sector and country of residence, and whole counts.

Source: OECD, Patent Database, September 2006, based on a list of patents selected by the EPO. Sector classifications are based on the Eurostat sector attribution algorithm. 


\section{DSTI/DOC(2007)4}

\section{A.2. Measurement of global knowledge flows}

The share of international co-inventions in nanotechnology patent applications is shown in Figure 24 . Small economies tend to have a large ratio and leading countries or economies tend to have a small ratio in the international co-inventions. The ratio of co-invented patent applications is notably high in Asian countries except for Korea and Japan. China and Chinese Taipei, in particular, have more than double the ratio of international co-inventions in comparison to the total EPO applications. This is quite different from observations in scientific publications. In scientific publications, the ratio of international co-authorship in Asian countries is usually smaller than in European countries (Igami and Saka, 2007).

\section{Figure 24. Share of international co-inventions in the nanotechnology patent applications} (1978-2005)

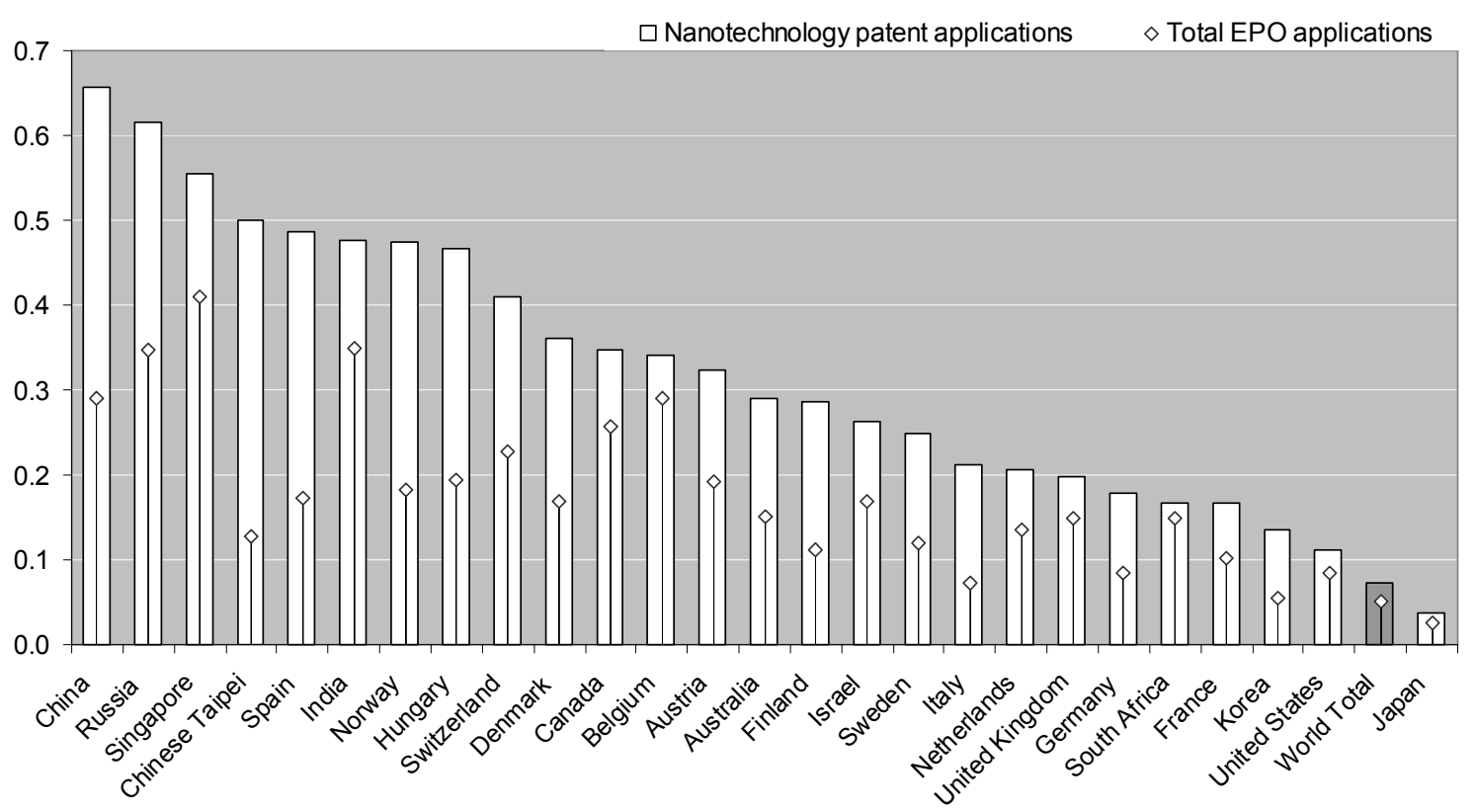

Note 1: Patent counts are based on the earliest priority date, the inventor's country of residence, and whole counts.

Note 2: The graph only covers countries/economies with more than 10 EPO applications from 1978-2005.

Source: OECD, Patent Database, September 2006, based on a list of patents selected by the EPO.

\section{A.3. Share of IPC and frequently used key phrases}

The share of IPC in the nanotechnology patent applications from 1999 to 2001 is shown in Figure 25. The top 15 IPC in this period are almost the same as those which are obtained from analysis on all nanotechnology patent applications from 1978 to 2005 (OECD, 2006).

The share of IPC has been changing over time. H01L had the largest share in the early 1990s, followed by A61K, G11B, and G01N. The share of A61K surged from $11.5 \%$ in the early 1990 s to $15 \%$ in the mid-1990s and decreased to $8.5 \%$ in the early 2000s. Similar trends are also observed in H01S. The share of G11B and G02F has been decreasing over time. The share of H01J, B01J, G03F, G11C, and C12Q shows notably a rapid increase from the mid-1990s to the early 2000 s.

Table 6 shows the most frequent usages of key phrases in the title of patent applications from 1999 to 2001. The key phrases analysis reveals a more detailed view of recent activities in the application fields. 
Key phrases which characterise the nanotechnology patent applications have been varying over time. For example, the most frequently used key phrase in H01L in the period 1989-1991 is "Quantum semiconductor device employing quantum boxes". The top three key phrases include the word "Quantum". Meanwhile, the top three key phrases in H01L do not have the word "Quantum" in the period 1999-2001. The key phrases specify more concrete technologies such as "Semiconductor memories". The trends likely show the development of electronic devices in which fundamental concepts converged into specific technologies over time.

The changes in key phrases also likely indicate the shape of forthcoming technologies. The continuous decrease of G11B and increase of G11C likely represents technological trends in storage technologies from the conventional optical or magnetic recordings to the recordings based on MARM or ultimately molecular memory devices.

Figure 25. Top 15 IPC in nanotechnology patent applications to EPO

(1989-1991, 1994-1996, and 1999-2001)

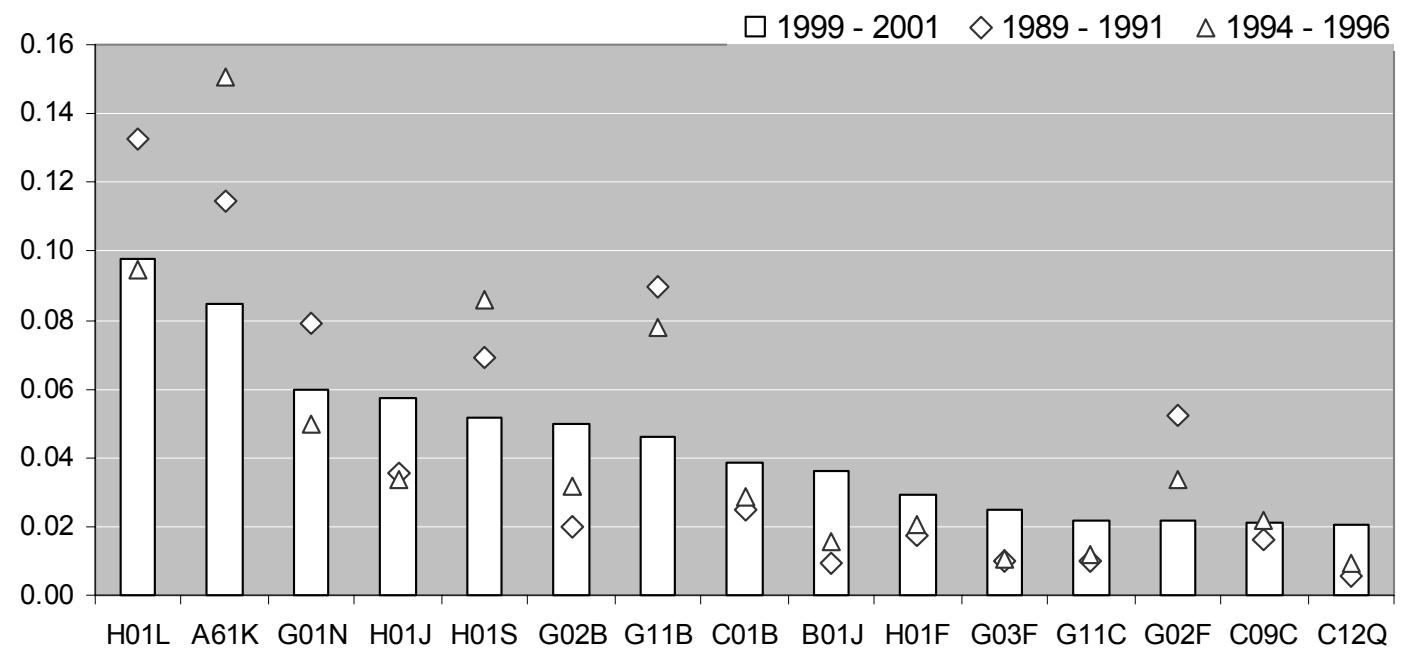

Note 1: Patent counts are based on the earliest priority date and fractional counts.

Note 2: Major IPC featured:

H01L: Semiconductor devices; electric solid state devices not otherwise provided for

A61K: Preparations for medical, dental, or toilet purposes

G01N: Investigating or analysing materials by determining their chemical or physical properties

H01J: Electric discharge tubes or discharge lamps

H01S: Devices using stimulated emission

G02B: Optical elements, systems, or apparatus

G11B: Information storage based on relative movement between record carrier and transducer

C01B: Non-metallic elements; compounds thereof

B01J: Chemical or physical processes

H01F: Magnets; inductances; transformers; selection of materials for their magnetic properties

G03F: Photomechanical production of textured or patterned surfaces

G11C: Static stores

G02F: Devices or arrangements, the optical operation of which is modified by changing the optical properties of the medium of the devices or arrangements for the control of the intensity, colour, phase, polarisation or direction of light

C09C: Treatment of inorganic materials, other than fibrous fillers, to enhance their pigmenting or filling properties

$\mathrm{C} 12 \mathrm{Q}$ : Measuring or testing processes involving enzymes or micro-organisms

Source: OECD, Patent Database, September 2006 based on a list of patents selected by the EPO. 


\section{Box 1. Identification of key phrases}

Key phrases in titles of the nanotechnology patent applications were identified through four steps. i) Segmenting titles: Titles were divided into phrases by stop words. Stop words are commonly used and not essentially important words for expressing technologies like "the", "to", etc. In order to avoid interference in the analysis, stop words were eliminated in this process. ii) Word frequency analysis: Frequency of words in titles of the nanotechnology patent applications, except stop words, was counted. iii) Weighting of phrases: Phrases identified in step 1 were weighted by word frequencies. For example, the weight of "carbon nanotubes" is evaluated as 150, if word frequencies of "carbon" are 100 and "nanotubes" are 50. iv) Identification of key phrases: Phrases were ordered by their weight and the top three phrases were identified as key phrases.

Table 6. Key phrases in top 15 IPC (1999-2001)

\begin{tabular}{|c|c|}
\hline IPC & Keywords in title \\
\hline H01L & $\begin{array}{l}\text { Semiconductor Device Manufacturing Method; Semiconductor Memory Device Using Magneto Resistive Effect Element; } \\
\text { Semiconductor Memory Device Including Memory Cell Portion }\end{array}$ \\
\hline A61K & $\begin{array}{l}\text { Pharmaceutical Compositions Comprising Drug; Compositions Containing Inclusion Complexes; Cosmetic } \\
\text { Compositions Containing Molecular Adducts }\end{array}$ \\
\hline H01S & $\begin{array}{l}\text { Circular Polarization Spin Semiconductor Laser Using Magnetic Semiconductor; Semiconductor Laser Using Five- } \\
\text { Element Compound Semiconductor; Strained Quantum Well Type Semiconductor Laser Device }\end{array}$ \\
\hline G01N & $\begin{array}{l}\text { Scanning Type Probe Microscope Probe; Delay Time Modulation Femtosecond Time-Resolved Scanning Probe } \\
\text { Microscope Apparatus; Probe Manufacturing Method }\end{array}$ \\
\hline G11B & $\begin{array}{l}\text { Optical Recording Method Using Optical Recording Medium; Near-Field Optical Recording Apparatus Assistively } \\
\text { Heating Recording Medium; Recording Magnetic Recording Information }\end{array}$ \\
\hline $\mathrm{H} 01 \mathrm{~J}$ & $\begin{array}{l}\text { Electron Beam Lithography Method; Charged Particle Beam Exposure Device Incorporating Beam Splitting; Electron } \\
\text { Emitting Device Based Flat Panel Display Apparatus }\end{array}$ \\
\hline C01B & $\begin{array}{l}\text { Carbon Nanowall Producing Method; Producing Carbon Nanotubes Using; Carbon Nanotubes Using Metal Catalyst } \\
\text { Layer }\end{array}$ \\
\hline G02B & $\begin{array}{l}\text { Optical Photonic Crystal Condensing Device; Optical Element Using One-Dimensional Photonic Crystal; Single Mode } \\
\text { Photonic Crystal Optical Fiber }\end{array}$ \\
\hline G02F & $\begin{array}{l}\text { Optical Device Comprising Optical Modulator; Full Optical Type Optical Element; Optical Wavelength-Division- } \\
\text { Multiplexed Cross-Connect Incorporating Optically Controlled Optical Switch }\end{array}$ \\
\hline $\mathrm{H} 01 \mathrm{~F}$ & Magnetic Material Manufacturing Method; Magnetic Alloy Thin Film; Magnetic Engraving Method \\
\hline G03F & $\begin{array}{l}\text { Extreme Ultraviolet Soft X-Ray Projection Lithographic Method System; Nano Imprint Lithography Method Using; } \\
\text { Device Manufacturing Method Using }\end{array}$ \\
\hline $\mathrm{B} 01 \mathrm{~J}$ & Probe Array Producing Method; Production Method Thereof; Spotting Method Using \\
\hline C09C & $\begin{array}{l}\text { Hydrophobic Inorganic Fine Particles Production Process; Pigment Particles Comprising Particles; Aqueous Dispersion } \\
\text { Comprising Inorganic Pigment-Cationic Resin Composite Fine Particles }\end{array}$ \\
\hline G11C & $\begin{array}{l}\text { Semiconductor Memory Device Using Magneto Resistive Element; Semiconductor Memory Device Using Resonant- } \\
\text { Tunneling Transistor; Electrochemical Molecular Memory Device }\end{array}$ \\
\hline C12Q & $\begin{array}{l}\text { Molecular Detection Method Using; Nucleic Acids Using Electronic Detection; Preparing Peptide Nucleic Acid Probe } \\
\text { Using Polymeric Photoacid Generator }\end{array}$ \\
\hline
\end{tabular}

Source: OECD, Patent Database, September 2006 based on a list of patents selected by the EPO. 


\section{A.4. Trends in patent citations and NPL citations identified via international searches and European searches}

Trends in the backward citations identified via international searches and European searches are shown in Figure 26. Four types of backward citations are shown: patent citations identified via European searches, patent citations identified via international searches, NPL citations identified via European searches, and NPL citations identified via international searches. The number of citations identified via European searches has been constant since the early 1990s except for 2002 and 2003. In contrast, the number of backward citations identified by the international search has been increasing steadily. In 2001, citations identified via international searches accounted for almost $70 \%$ of total citations.

Figure 26.

Trends in patent citations and NPL citations identified via international searches and European searches

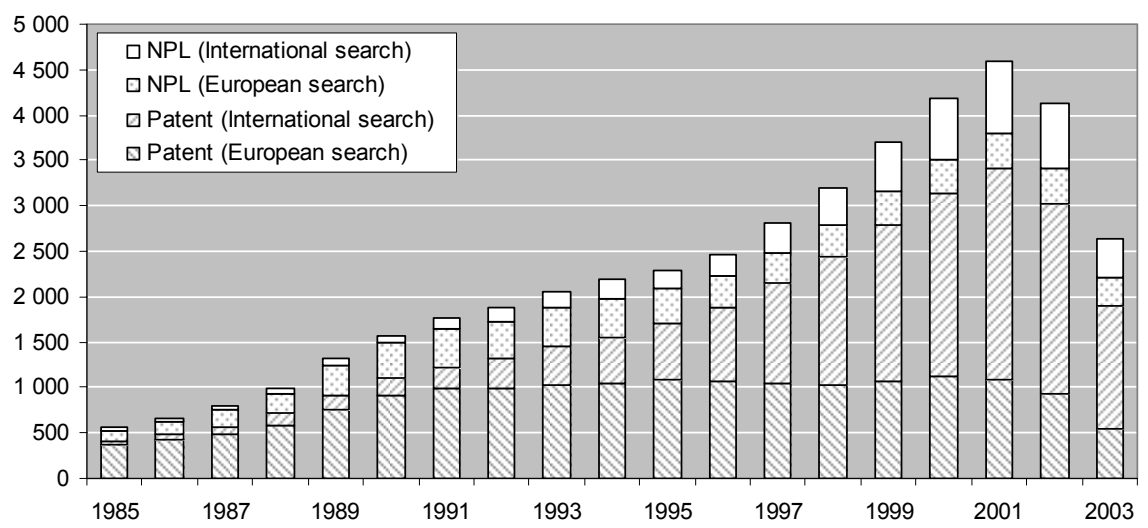

Note: Patent counts are based on the earliest priority date. Figure shows three years' moving average.

Source: OECD, EPO citations database September 2006 and OECD, Patent Database, September 2006, based on a list of patents selected by the EPO. 


\section{ANNEX B \\ GLOSSARY OF PATENT TERMINOLOGY AND INDICATORS}

\section{Applicant}

The person or company that applies for the patent and intends to "work" the invention (i.e. to manufacture or licence the technology). In most countries the inventor(s) does not necessarily have to be the applicant. In the United States, applicants must be the inventor(s), except in a few exceptional circumstances (e.g. legal representatives of a deceased inventor may make a patent application).

\section{Applicant country}

The applicant is the patentee at the date of the application. When counting patents by geographical area, they can be attributed to the country of residence of the applicant. Patent counts by applicant concentrate on patent "ownership" (i.e. the number of patents owned by residents of each country). For example, a patent application filed by IBM Belgium is allocated to Belgium, even though the ultimate ownership of IBM Belgium might be in another country.

\section{Application date}

The patent application date is the date on which the patent office received the patent application.

\section{Backward citations}

Backward citations are citations from patent applications to prior arts. They represent the influence of past inventive activities on the patent applications. The ratio of the non-patent literature in backward citations is a proxy for measuring linkages between scientific and inventive activities.

\section{Citations}

Citations may be made by the examiner or the applicant/inventor. They comprise a list of references that are believed to be relevant prior art and which may have contributed to the "narrowing" of the original application. The examiner can also cite references from technical journals, textbooks, handbooks and sources. The citations practices of the EPO differ substantially from those of the USPTO. Applicants to USPTO are legally required to include a full list of prior art known or believed to be relevant ("duty of candor"). At EPO, no such requirement exists for applicants. See also Backward citations and Forward citations.

\section{Equivalent}

A patent that relates to the same invention and shares the same priority application as a patent from a different issuing authority. 


\section{European Patent Office (EPO)}

The European Patent Office (a regional patents office) was created by the EPC to grant European patents, based on a centralised examination procedure. By filing a single European patent application in one of the three official languages (English, French and German), it is possible to obtain patent rights in all the EPC member and extension countries by designating the countries in the EPO application. The EPO is not an institution of the European Union.

\section{Forward citations}

Forward citations are citations to nanotechnology patent applications from other patent applications. Counts of forward citations are considered to be indicators of patents' economic or technological value.

\section{Intellectual property rights (IPR)}

IPR allows people to assert ownership rights on the outcomes of their creativity and innovative activity in the same way that they can own physical property. The four main types of intellectual property rights are: patents, trademarks, design and copyrights.

\section{International Patent Classification (IPC)}

The International Patent Classification, which is commonly referred to as the IPC, is based on an international multilateral treaty administered by WIPO. The IPC is an internationally recognised patent classification system, which provides a common classification for patents according to technology groups. The IPC is a hierarchical system in which the whole area of technology is divided into a range of sections, classes, subclasses and groups. There are eight sections that are broken down into classes and subclasses. IPC is periodically revised in order to improve the system and to take account of technical development. The current (eighth) edition of the IPC entered into force on 1 January 2006.

\section{Inventor country}

Country of residence of the inventor, which is frequently used to count patents in order to measure inventive performance.

\section{Japan Patent Office (JPO)}

The JPO administers the examination and granting of patent rights in Japan. The JPO is an agency of the Ministry of Economy, Trade and Industry (METI).

\section{Non-patent literature citations (or Science Linkage)}

Non-patent literature (NPL) citations are citations to non-patent literatures associated with inventions claimed in the patent applications. Since the majority of NPL citations consist of citations to scientific journals, it is likely that the ratio of NPL citations in patent applications is a good indicator to assess science-intensiveness of inventive activities. 


\section{OECD triadic patent families}

The triadic patent families are defined at the OECD as a set of patents taken at the European Patent Office (EPO), the Japan Patent Office (JPO) and the US Patent \& Trademark Office (USPTO) that share one or more priorities. Triadic patent families data are consolidated to eliminate double counting of patents filed in different offices (i.e. regrouping all the interrelated priorities in EPO, JPO and USPTO patent documents).

\section{Patent}

A patent is an intellectual property right issued by authorised bodies to inventors to make use of, and exploit their inventions for a limited period of time (generally 20 years). The patent holder has the legal authority to exclude others from commercially exploiting the invention (for a limited time period). In return for the ownership rights, the applicant must disclose the invention for which protection is sought. The trade-off between the granting of monopoly rights for a limited period and full disclosure of information is an important aspect of the patenting system.

\section{Patent Cooperation Treaty (PCT)}

As of July 2005, there were 128 countries party to this treaty, which was signed in 1970 and entered into force in 1978. The PCT provides the possibility to seek patent rights in a large number of countries by filing a single international application (PCT application) with a single patent office (receiving office). The PCT procedure consists of two main phases: $a$ ) an "international phase"; and b) a PCT "national/regional phase". PCT applications are administered by the World Intellectual Property Organisation (WIPO).

\section{Prior art}

Previously used or published technology that may be referred to in a patent application or examination report, i.e. a) in a broad sense, technology that is relevant to an invention and was publicly available (e.g. described in a publication or offered for sale) at the time an invention was made; or $b$ ) in a narrow sense, any such technology which would invalidate a patent or limit its scope. The process of prosecuting a patent or interpreting its claims largely consists of identifying relevant prior art and distinguishing the claimed invention from that prior art. The objective of the search process is to identify patent and nonpatent documents constituting the relevant prior art in order to determine whether the invention is novel and includes an inventive step.

\section{Priority date}

The priority date is the first date of filing of a patent application, anywhere in the world (normally in the applicant's domestic patent office), to protect an invention. The priority date is used to determine the novelty of the invention, which implies that it is an important concept in patent procedures. For statistical purposes, the priority date is the closest date to the date of invention.

\section{Publication}

In most countries, a patent application is published 18 months after the priority date. For example, all pending EPO and JPO patent applications are published 18 months after the priority date. Prior to a change in rules under the American Inventors Protection Act of 1999, USPTO patent applications were held in confidence until a patent was granted. Patent applications filed at the USPTO on or after 29 November 2000 are required to be published 18 months after the priority date. However, there are certain exceptions to the publication of pending patents. For example, an applicant can ask (upon filing) for 
the patent not to be published by certifying that the invention disclosed in the application has not and will not be the subject of an application filed in another country.

\section{Publication date}

The date on which the patent application is published (i.e. the information is available to the public). This normally occurs 18 months after the priority date.

\section{Time-lag in backward citations (citing half-life)}

The number of months which account for $50 \%$ of the total backward citations from patent applications to prior patent publications. This indicator is known as the "citing half-life" in bibliometric analysis.

\section{United States Patent and Trademark Office (USPTO)}

The USPTO administers the examination and granting of patent rights in the United States. It falls under the jurisdiction of the US Department of Commerce.

\section{World Intellectual Property Organization (WIPO)}

An intergovernmental organisation responsible for the negotiation and administration of various multilateral treaties dealing with the legal and administrative aspects of intellectual property. In the patent area, the WIPO is notably in charge of administering the Patent Cooperation Treaty (PCT) and the International Patent Classification system (IPC).

Sources: Glossary of patent terminology, Compendium of Patent Statistics 2006, OECD. 


\section{REFERENCES}

Arundel, A. and Kable, I. (1998), "What Percentage of Innovations are Patented? Empirical Estimates for European Firms", Research Policy, 27, 127 - 141.

Barabási, A.L. and Albert, R. (1999), "Emergence of Scaling in Random Networks", Science, 286, 509-512.

Binning, G., Rohrer, H., Gerber, Ch. and Weibel, E. (1982), "Surface Studies by Scanning Tunneling Microscopy", Physical Review Letters, 49, 1, 57-61.

Binning, G., Quate, C.F. and Gerber, Ch. (1986), “Atomic Force Microscope”, Physical Review Letters, 56, 9, 930-933.

Börner, K., Chen, C. and Boyack, K. W. (2003), "Visualizing Knowledge Domains", Annual Review of Information Science and Technology, 37, 179-255.

Boyack, K. W. (2004), “Mapping Knowledge Domains: Characterizing PNAS”, PNAS, 101, 1, 5192-5199.

Chen, C. (1999), "Visualising Semantic Spaces and Author Co-citation Networks in Digital Libraries", Information Processing \& Management, 53, 401-420.

Chen, C. and Paul, R.J. (2001), "Visualising a Knowledge Domain's Intellectual”, Computer, 34, 3, 65-71.

Deurenberg R. (1993), "Journal Deselection in a Medical University Library by Ranking Periodicals Based on Multiple Factors", The Bulletin of the Medical Library Association, 81, 3, 316-9.

Feynman, R.P. (1959), “There's Plenty of Room at the Bottom”, Annual Meeting of the American Physical Society at the California Institute of Technology.

Garfield, E., Sher, I.H. and Torpie, R.J. (1964), "The Use of Citation Data in Writing the History of Science”, Institute for Scientific Information, Philadelphia.

Glänzel, W., Meyer, M., Du Plessis, M., Thijs, B., Magerman, T., Schlemmer, B., Debackere, K. and Veugelers, R. (2003), "Nanotechnology, Analysis of an Emerging Domian of Scientific and Technological Endeavour", Steunpunt O\&O Statistieken.

Hall, B.H., Jaffe, A.B. and Trajtenberg, M. (2001), "The NBER Patent Citations Data File: Lessons, Insights and Methodological Tools", NBER Working Paper No. 8498.

Harhoff, D., Narin, F., Scherer, F.M. and Vopel, K. (1999), "Citation Frequency and the Value of Patented Inventions", The Review of Economics and Statistics, 81, 3, 511-515.

Harhoff, D., Scherer, F.M. and Vopel, K. (2003), "Citations, Family Size, Opposition and the Value of Patent Rights", Research Policy, 32, 1343-1363. 
Heinze, T. (2004), "Nanoscience and Nanotechnology in Europe: Analysis of Publications and Patent Applications including Comparisons with the United States", Nanotechnology Law \& Business, 1, 4, 427-445.

Henderson, R., Jaffe, A.B. and Trajtenberg, M. (1998), "Universities as a Source of Commercial Technology: A Detailed Analysis of University Patenting, 1965-1988", The Review of Economics and Statistics, 80, 1, 119-127.

Huang, Z., Chen, H., Chen, Z.K. and Roco, M.C. (2004) "International Nanotechnology Development in 2003: Country, Institution, and Technology Field Analysis Based on USPTO Patent Database".

Igami, M. and Saka, A. (2007), "Capturing the Evolving Nature of Science, Development of New Scientific Indicators and Mapping of Science", STI Working Paper 2007/1, OECD Directorate for Science, Technology and Industry.

Iijima, S. (1991), “Helical Micro-tubules of Graphitic Carbon”, Nature, 345, 56-58.

Jaffe, A.B. and Trajtenberg, M. (1998), "International Knowledge Flows: Evidence from Patent Citations", Economics of Innovation and New Technology, 8, 105-136.

Jaffe, A.B., Trajtenberg, M. and Fogarty, M.S. (2000), "Knowledge Spillovers and Patent Citations: Evidence from a Survey of Inventors", The American Economic Review, 90, 2, 215-218.

Kroto, H.W., Heath, J.R., O'Brien, S.C., Curl, R.F. and Smalley, R.E. (1985), "C60 : Buckminsterfullerene", Nature, 318, 162-163.

Kubo, R. (1962), “Electronic Properties of Metallic Fine Particles. I.”, Journal of the Physical Society of Japan, 17, 6, 975-986.

Lanjouw, J,O., and Schankerman, M. (1999), “The Quality of Ideas: Measuring Innovation with Multiple Indicators”, NBER Working Paper No. W7345.

Mane, K. K. and Börner, K (2004), "Mapping Topics and Topic Bursts in PNAS", PNAS, 101, 1, 5287-5290.

Meyer, M. (2000), "What is Special about Patent Citations? Differences between Scientific and Patent Citations", Scientometrics, 49, 1, 93-123.

Meyer, M. (2006a), "Are Patenting Scientists the Better Scholars? An Exploratory Comparison of Inventor-authors with their Non-inventing Peers in Nano-science and Technology", Research Policy, $35,1646-1662$.

Meyer, M. (2006b), "What do we Know about Innovation in Nanotechnology? Some Propositions about an Emerging Field between Hype and Path-dependency", paper presented at SPRU 40th Anniversary Conference - The Future of Science, Technology and Innovation Policy, SPRU, Brighton, East Sussex, United Kingdom.

Available at http://www.sussex.ac.uk/Units/spru/events/ocs/viewabstract.php?id=76

Murray, F. (2002), "Innovation as Co-evoluton of Scientific and Technological Networks: Exploring Tissues Engineering", Research Policy, 35, 1646-1662. 
Narin, F., Hamilton, K.S. and Olivastro, D. (1997), “The Increasing Linkage between U.S. Technology and Public Science”, Research Policy, 26, 317-330.

National Institute of Science and Technology Policy (2005), "Science and Technology Foresight Survey, Delphi Analysis", NISTEP Report No. 97.

Newman, M. Barabasi, A.L. and Watts, D.J., (2006), "The Structure And Dynamics of Networks", Princeton Studies in Complexity, Princeton University Press.

OECD (2006), Compendium of Patent Statistics, OECD, Paris.

Scheu, M., Veefkind, V., Verbandt, Y., Molina Galan, E., Absalom, R. and Förster, W. (2006), "Mapping nanotechnology patents: The EPO approach", World Patent Information, 28, 204-211.

Shiffrin, R.M and Börner, K. (2004), "Mapping Knowledge Domains”, PNAS, 101, 1, 5183-5185.

Small, H. and Sweeney, E. (1985a), "Clustering the Science Citation Index using Co-citations. I. A Comparison of Methods", Scientometrics, 7, 3-6, 391-409.

Small, H., Sweeney, E., and Greenlee, E. (1985b), "Clustering the Science Citation Index using Co-citations. II. Mapping Science", Scientometrics, 8, 5-6, 321-340.

von Wartburg, I., Teichert, T. and Rost, K. (2005), "Inventive Progress Measured by Multi-stage Patent Citation Analysis", Research Policy, 34,1591-1607.

Webb, C., Dernis, H., Harhoff, D., and Hoisl, K. (2005), "Analysing European and International Patent Citations: A Set of EPO Patent Database Building Blocks", STI Working Paper 2005/9, OECD Directorate for Science, Technology and Industry.

Zhou, P. and Leydesdorff, L. (2006), "The Emergence of China as a Leading Nation in Science", Research Policy, 35, 83-104.

Zucker, L.G., Darby, M.R., Furner, J., Liu, R.C. and Ma, H. (2006), “ Minerva Unbound: Knowledge Stocks, Knowledge Flows and New Knowledge Production”, NBER Working Paper No. 12669. 